\title{
The Economics of the Marriage Contract: Theories and Evidence
}

\author{
Niko Matouschek Northwestern University \\ Imran Rasul University College London
}

\begin{abstract}
We analyze the role of the marriage contract. We first formalize three prominent hypotheses on why people marry: marriage provides an exogenous payoff to married partners, it serves as a commitment device, and it serves as a signaling device. For each theory we analyze how a reduction in the costs of divorce affects the propensity to divorce for couples at any given duration of marriage. We then use individual marriage and divorce certificate data from the United States to bring these alternative views of the marriage contract to bear on the data. We exploit variations in the timing of the adoption of unilateral divorce laws across states to proxy a one-off and permanent reduction in divorce costs. The results suggest that the dominant reason that couples enter into a marriage contract is that it serves as a commitment device.
\end{abstract}

\section{Introduction}

Marriage markets have changed dramatically since Becker's $(1973,1974)$ seminal theory of marriage. Foremost among these developments in both the United States and Western Europe have been the large changes in divorce rates, the decline in marriage rates, and the general weakening of the traditional family structure. In this article, we argue that in order to understand the cause and effect of these changes, it is necessary to establish the reasons individuals decide to marry in the first place.

In Becker's original work and in the enormous body of literature it inspired, two individuals marry when there is a positive surplus from their union relative to the situation if the two remain single. Such gains may arise from specialization in home and market production, economies of scale, the provision of insurance, and risk sharing, among others.

The motivation for this article derives from noting that these explanations

We have benefited from discussions with Oriana Bandiera, James Banks, Heski Bar-Isaac, Pedro Carneiro, Iftikhar Hussain, Elizabeth Peters, Riccardo Puglisi, Stephane Mechoulan, Frederic RobertNicoud, Scott Schaefer, Scott Stern, Daniel Sturm, and seminar participants at the Cornell Evolving Family Conference 2006. We also thank the editor, Dennis Carlton, and an anonymous referee for their comments. All remaining errors are our own.

[Journal of Law and Economics, vol. 51 (February 2008)]

(C) 2008 by The University of Chicago. All rights reserved. Printed in U.S.A. 0022-2186/2008/5101-03\$10.00 
relate to why two individuals prefer to be together rather than remain single. They offer less insight into why individuals prefer to marry and enter into a marriage contract rather than cohabit. In this article, we take a contractual view of marriage and directly address the following question: what is the role of the marriage contract? To answer this, we formalize three prominent hypotheses on why people marry, rather than cohabit, and analyze the predictions that each underlying theory of marriage has on marriage market outcomes. We then bring these alternative models of marriage to the data and present evidence to empirically distinguish among them.

We first develop three stylized dynamic models to formalize the main functions of the marriage contract that have been discussed in the law and economics literature (for an overview, see Dnes and Rowthorn 2002). We follow this literature in viewing marriage as a contract that makes it more costly for the partners to exit their relationship than it would cost to exit if they were cohabiting. Underlying this view is the belief that bargaining over a divorce does not fit into the paradigm of costless Coasean bargaining. Instead, a variety of transaction costs are likely to impose inefficiencies on most, if not all, divorce negotiations. Transaction costs may, for instance, arise because of liquidity constraints or asymmetric information about the value that each partner places on continuing the marriage. The fees paid to divorce lawyers and legally imposed restrictions, such as mandatory separation requirements, are other examples of transaction costs that are pertinent in divorce negotiations. These costs do not arise, or are at least severely mitigated, when cohabiting couples break up. ${ }^{1}$

The costs of entering into a marriage contract are, therefore, the same in all the models-being in a marriage, rather than cohabiting, always increases the costs of exiting a relationship. The benefits, however, differ. In the first model, the benefit of marriage is simply an exogenously given payoff that captures the extra utility couples derive from following social custom (Cohen 1987, 2002). In the second model, marriage acts as a commitment device that fosters cooperation and/or induces partners to make relationship-specific investments (Brinig and Crafton 1994; Scott 1990, 2002; Wydick 2004). In the third model, the marriage contract serves as a signaling device that can be used by one partner to credibly signal his or her true love (Bishop 1984; Rowthorn 2002; Trebilcock 1999).

The comparative static we focus on is how a decline in divorce costs affects the propensity to divorce - the likelihood of divorce in any given year of marriage, conditional on the marriage having remained intact up until that year. In all the

\footnotetext{
${ }^{1}$ As will be discussed in detail in the next section, the view that divorce involves transaction costs is widespread in the law and economics literature and among legal practitioners. This view is also reflected in the current public debate about divorce law reform in New York. For instance, in her 2006 State of the Judiciary address, the chief justice of New York stated that "divorce takes too long and costs much too much - too much money, too much agony, too hard on the children" (Kaye 2006; Hakim 2006). In the economics literature, Peters (1986) and Friedberg and Stern (2004) present evidence of such transaction costs being considerable.
} 
models, a change in divorce costs affects divorce propensity through two channels. First, lower divorce costs affect the incentive of existing married couples to divorce. We label this the "incentive effect" of divorce costs. Second, lower divorce costs affect the composition of those couples who choose to marry in the first place. We label this the "selection effect" of divorce costs.

All the models have the same intuitive prediction that the incentive effect varies by the time spent living under the lower divorce costs. In particular, as divorce costs fall (i) the divorce propensity is higher in the first few years spent living under lower divorce costs, so badly matched married couples break up earlier; and (ii) as badly matched couples break up earlier, the divorce propensity is lower for couples who have been married under lower divorce costs for many years. Hence, the incentive effect is negative in the first few years after the decline in divorce costs-so lower divorce costs increase divorce propensity-and it is positive in later years.

Unlike the incentive effect, predictions on the selection effect of divorce costs differ depending on the underlying theory of marriage. When marriage serves as a commitment device, a reduction in divorce costs can induce couples of relatively low match quality not to marry. Because the marginal couple that marries is of a higher match quality, this increases the average match quality of married couples, which, in turn, reduces divorce propensity at all marital durations. In such a commitment model of marriage, the selection effect can, therefore, be positive; namely, a decrease in divorce costs leads to a decrease in divorce propensity, all else being equal.

In contrast, the selection effect is negative when the primary purpose of marriage is to serve as a signaling device or to bestow exogenous benefits on couples. In these models, a reduction in divorce costs mitigates the costs of marriage but does not affect its benefits. As a result, couples of relatively low match quality, who do not get married when divorce costs are high, now prefer to marry when divorce costs are low. This situation reduces the average match quality of married couples, which, in turn, leads to an increase in divorce propensity at all marital durations. Both of these theories of marriage, therefore, predict that lower divorce costs reduce the match quality of the marginal and average marriage and, hence, should raise the divorce propensity, all else being equal.

We then take these predictions on the incentive and selection effects of lower divorce costs to the data. The aims of the empirical analysis are to, first, explore if the theoretical predictions on the incentive effect of lower divorce costs on divorce propensity - which are the same in all underlying models of marriageare actually borne out in the data. Second, we present evidence on the selection effect of lower divorce costs on divorce propensity. This sheds light on which theory best matches the observed patterns in divorce propensities.

Our empirical analysis exploits individual marriage and divorce certificate data for the United States. This is a rich data source that has not previously been exploited in the economics literature in such a disaggregated way. We construct 
divorce propensities by duration, state, and year of divorce for all marriages that occurred in 33 states after 1968 and were dissolved by divorce before 1995 .

To measure a large and permanent reduction in divorce costs, we exploit crossstate variations in the timing of moves from mutual-consent to unilateral divorce laws. This is perhaps the single most important divorce law reform in the United States in the past generation. Between 1968 and 1977, the majority of states passed such laws, moving from a fault-based regime in which the dissolution of marriage required the mutual consent of both spouses to one in which either spouse could unilaterally file for divorce and no fault had to be proved. It has long been argued in the law and economics literature that these reforms significantly reduced the costs of exiting marriage (Bishop 1984; Brinig and Crafton 1994; Trebilcock 1999; Rowthorn 2002; Scott 1990, 2002).

The view that mutual consent, or fault-based, divorce involves significant transaction costs is also commonplace within the legal profession. In New York, which has fault-based divorce law, the recent report of the Matrimonial Commission (2006), written by a panel of 32 leading practitioners of family law in the state, states that "New York's fault-based divorce system has a direct impact on the manner in which, and the speed with which, matrimonial matters proceed. Substantial evidence, derived from the public hearings held by the Commission and the professional experience of the Commission members, leads us to conclude that fault allegations and fault trials add significantly to the cost, delay and trauma of matrimonial litigation and are, in many cases, used by litigants to achieve a tactical advantage in matrimonial litigation."

Given the disaggregated nature of our data, we identify the incentive and selection effects of lower divorce costs by exploiting the variation in divorce propensities in marriages of different durations but within the same state and year of divorce. Hence, we are able to condition on unobserved state-specific trends-such as changes in social attitudes or labor market characteristics- that may drive both the adoption of unilateral divorce laws and marriage market outcomes. This identification strategy allows us to address a key econometric concern that has plagued earlier studies on the effects of the liberalization of divorce laws on various marriage market outcomes.

With regard to the incentive effect, our main results are as follows. First, we find evidence of an incentive effect of lower divorce costs on divorce propensity, as proxied by the introduction of unilateral divorce laws. Second, this incentive effect varies according to how long the couple has been married under a unilateral divorce law. Married couples who live under unilateral divorce laws for only a few years are more likely to divorce, and those who live for more years under unilateral divorce laws are less likely to divorce, all else being equal. In other words, the incentive effect is at first negative and then positive. This evidence is in line with the predictions of all the theories of marriage.

With regard to the selection effect, we find evidence of a positive selection effect of lower divorce costs on divorce propensity. Namely, those couples who marry after unilateral divorce laws are in place, and hence when divorce costs 
are lower, are significantly less likely to divorce during marriage, other things being equal. This result holds conditioning on the incentive effects of lower divorce costs already discussed and conditioning on state-specific trends in divorce propensities. The result suggests that reducing divorce costs leads to the marginal newly married couple being, in some sense, "better matched" than those previously married. This positive selection effect is consistent with only the commitment model of marriage. While we do not doubt that there are elements of all these hypotheses at play in the marriage market, the evidence suggests that the dominant role of the marriage contract is to act as a commitment device.

The contributions of the article are threefold. First, we develop and empirically test three models of the role of a marital contract. Second, our results help explain some puzzling findings in the earlier literature estimating the effect of unilateral divorce laws on the aggregate divorce rate. For example, both Gruber (2004) and Wolfers (2006) find that the effects of unilateral divorce on aggregate divorce rates disappear around a decade after its introduction. Here we determine precisely why this is so. Because the marriage contract serves primarily as a commitment device, when divorce costs fall, only couples with a higher match quality remain willing to marry. This situation reduces the divorce rate in the long run, as these better-matched couples form a greater share of all married couples in steady state. Indeed, the last 20 years has been the longest period of sustained decline in divorce rates in America since records began to be kept in 1860.

Third, our results speak directly to the public policy debate on the design of efficient divorce laws. The reform of these laws is a controversial policy issue that has received widespread public attention. ${ }^{2}$ Our findings give support to those who argue that divorce costs can be too low and that when they are too low, the very purpose of the marriage contract is undermined.

The article is organized as follows. Section 2 discusses the related theoretical and empirical literature. Section 3 formalizes in turn three functions of the marriage contract. Section 4 discusses unilateral divorce laws and describes our data and empirical method. Section 5 presents the main results and robustness checks. Section 6 concludes. All proofs are in Appendix A.

\section{Related Literature}

Becker's $(1973,1974)$ seminal work inspired a vast literature on the economics of marriage (for overviews of the literature, see, for instance, Bergstrom 1997; Ermisch 2003; Weiss 1997). In general, however, this literature sheds more light on why people prefer to be in a couple rather than single than on why couples enter into marital contracts per se. However, economists have recently started

\footnotetext{
${ }^{2}$ See, for example, the discussion in Waite and Gallagher (2000) on the divergent views across interest groups on how divorce laws should be designed.
} 
to address the choice between marriage and cohabitation. For example, Brien, Lillard, and Stern (2006) estimate a structural model of the marriage market in which couples learn their match quality over time. They assume that, for exogenous reasons, the utility flows during relationships and the costs of dissolving them are different under marriage and cohabitation.

Wickelgren (2005) studies the effect of the change from mutual-consent divorce to unilateral divorce on spouses' investment incentives. Similar to our argument, he shows that divorce reform can affect divorce rates both directly and indirectly by changing selection into marriage. Since he focuses on bargaining over the marital surplus but largely abstracts from the choice between marriage and cohabitation, while we largely abstract from bargaining and focus on the choice between marriage and cohabitation, his study can be viewed as complementary to this article.

Wydick (2004) develops a model that is closely related to our commitment model. He also argues that being in a marriage, compared with cohabiting, makes it more costly for couples to break up and shows that in a repeated-game setting, marriage can foster cooperation. Also in line with our analysis, he finds that low-match-quality couples prefer cohabitation, while higher-match-quality couples prefer marriage. He does not, however, analyze the effects of lower divorce costs on selection into marriage. Chiappori, Iyigun, and Weiss (2005) integrate a model of marital bargaining into a marriage market framework to analyze the effects of changes in laws on the division of property in divorce. They also emphasize that these legal changes have different effects on existing married couples and newly matched couples.

In contrast to the economics literature, the contractual choice between marriage and cohabitation has been at the center of much attention in the field of law and economics (Dnes and Rowthorn 2002). This literature emphasizes the higher exit costs of marriage relative to those of cohabitation and has identified three main functions of the marriage contract: (i) couples derive utility from following social custom (Cohen 1987, 2002), (ii) marriage serves as a commitment device that fosters cooperation and investments (Brinig and Crafton 1994; Scott 1990, 2002), and (iii) it serves as a signaling device (Bishop 1984; Trebilcock 1999; Rowthorn 2002). Moreover, it is widely argued in this literature that the move from mutual-consent to unilateral divorce has lowered the costs of divorce and that this has undermined some of the functions of the marriage contract.

To turn to the empirical literature, a number of articles have studied the effects of this legal change on marriage and divorce rates and provide suggestive evidence for the existence of incentive and selection effects. Rasul (2005) uses state-level panel data to present evidence of a causal relationship between the adoption of unilateral divorce laws and declines in marriage rates. This finding suggests that couples are aware of divorce laws when they marry, which is a necessary condition for any selection effect to be present. Moreover, the fact that marriage rates have declined with the introduction of unilateral divorce hints that lower divorce costs 
may lead to positive selection into marriage, which is consistent with marriage serving predominantly as a commitment device. ${ }^{3}$

Trends in divorce rates are also informative. The doubling of divorce rates between 1965 and 1980 has been well documented. Less noted has been the decline in divorce rates since the mid-1980s. Indeed, the past 15 years have witnessed the longest sustained decline in divorce rates since records began to be kept. There has also been a convergence in divorce rates between states with and without unilateral divorce laws. Using state-level data from 1968 to 1988, Friedberg (1998) finds that the introduction of unilateral divorce led to significantly higher divorce rates. Wolfers (2006) extends Friedberg's sample to 2000 and reports that the effects of unilateral divorce disappear around a decade after its introduction. Gruber (2004) reports similar results using census data.

Our analysis highlights that divorce rates in states adopting unilateral divorce actually reflect two effects. First, under unilateral divorce law, divorce is less costly and, hence, more likely. This incentive effect implies that divorce rates should be higher in adopting states, other things being equal. Second, the composition of those who marry changes under unilateral divorce-a selection effect. Whether this change leads the divorce rate under unilateral divorce laws to be higher or lower than it is under mutual-consent laws depends on the underlying reason why individuals choose to marry. The long-run convergence in divorce rates in adopting and nonadopting states is, however, suggestive of a positive selection effect. ${ }^{4}$ As with the evidence from marriage rates, trends in divorce rates are consistent with marriage acting primarily as a commitment device.

While the literature suggests a positive selection effect, this evidence is not conclusive. Our key contributions relate to the fact that the existing literature ignores the effect of divorce laws on the composition of couples who marry. Our empirical method uses information on duration-state-year of divorce propensities to identify the incentive and selection effects of lower divorce costs. We identify each effect by exploiting variations in the divorce propensities in marriages of different durations but within the same state and year of divorce. Hence, we condition on unobserved state-specific trends that may drive the adoption of unilateral divorce and marriage market outcomes, thus mitigating a key econometric concern in earlier studies. These estimates then map back more precisely to underlying theories of marriage than do estimates obtained from analyzing any aggregate divorce rate series.

\section{Theory}

We formalize the three aforementioned hypotheses on the functions of the marriage contract that have been suggested in the law and economics literature.

\footnotetext{
${ }^{3}$ Of course, many other factors have also changed over time. For example, Goldin and Katz (2002) show how the diffusion of the contraceptive pill has affected marriage incentives for women.

${ }^{4}$ Weiss and Willis (1997) also hint at this possibility by using data from the National Study of the High School Class of 1972. Although it is not their focus, they find that couples married under unilateral divorce laws are less likely to divorce than are those married under mutual-consent laws. Mechoulan (2006) presents similar evidence from Current Population Survey data.
} 
For each hypothesis, we develop a simple dynamic model that makes precise how a change in divorce costs affects marriage and divorce behavior. ${ }^{5}$ There are three important features of our approach to modeling marriage.

First, we interpret marriage as a contract that makes it more costly for couples to separate than it would be if they were cohabiting. ${ }^{6}$ However, marriage contracts not only make separation more costly but also change a variety of other rights and obligations, such as custodial rights over children (Edlund 2005). We abstract from these other features of marital contracts and follow the lead of the law and economics literature in focusing on the increased separation costs of marriage. We do so also because the divorce law reform we focus on empirically had a first-order effect of reducing these costs of exiting marriage.

Second, and related to the first feature, we assume that the sole effect of divorce law reform was to reduce divorce costs and abstract from other potential effects, such as a loss of prestige in getting married, that may be due to sociological and psychological factors. We do so because we believe that while divorce law reform clearly reduced the costs of divorce, the evidence on such additional effects is much less clear-cut.

Third, we largely abstract from marital bargaining over quasi-rents. We do so to focus attention on the effect of divorce reform on separation costs, an issue that has been largely neglected in the economics of marriage literature and that is likely to be of first-order importance. Extending our analysis to allow for bargaining would complicate the analysis without changing the basic insights that we can empirically investigate.

\subsection{Exogenous Benefits of Marriage}

There is a unit mass of men and a unit mass of women. In period $d=0$, each man gets matched with one woman, and each couple learns the per-partner benefit, $b$, that can be realized in their relationship. ${ }^{8}$ In common with all the models we develop, these benefits, $b$, of being together might arise from any number of sources, including children or other relationship-specific assets.

We assume that $b$ is drawn from a distribution with cumulative distribution function $H(b)$ and support $[0, \infty)$. Each couple then decides whether to cohabit or to marry, after which time moves on to period $d=1$. At the beginning of

\footnotetext{
${ }^{5}$ The time-constrained reader may skip to Section 3.4, where we summarize the predictions of each model.

${ }^{6}$ There are two reasons why separation is more costly for married couples. First, there are stateimposed costs, such as minimum separation requirements, that married couples must incur before a divorce is granted. In contrast, cohabiting couples do not incur any such costs. Second, divorce typically involves bargaining, and the bargaining process is likely to be costly for a variety of reasons, including the presence of private information. While the breakup of a cohabiting couple may also involve costly bargaining, the bargaining costs are limited by the ability of partners to unilaterally terminate the relationship.

${ }^{7}$ Indeed, Wickelgren (2005) develops a model that allows for bargaining and reaches similar conclusions.

${ }^{8}$ Throughout, we assume that couples-whether cohabiting or married-consist of one woman and one man. We make this assumption solely for expositional convenience.
} 
$d=1$, each partner in a cohabiting couple realizes $b$, and each partner in a married couple realizes $b+B$, where $B>0$ is an exogenously given marriage benefit. This benefit captures the extra utility that the partners derive from publicly demonstrating their love.

Next, each partner in each couple learns the payoff $s \in[0, \infty)$ that he or she can realize by returning to the single pool. This outside option, $s$, is couple specific and is randomly drawn from a distribution $F(s)$. For simplicity, we assume that the payoff $s$ that can be realized by returning to the single pool is the same for the man and the woman in any couple. ${ }^{9}$

After the value of the outside option is realized, each partner decides whether to break up the current relationship and realize the outside option or whether to forgo the outside option and remain in the current relationship..$^{10}$ A breakup is costless for a cohabiting couple but involves a divorce cost $\gamma$ per partner if the couple is married. If a couple decides to break up, each partner realizes the outside option and potentially incurs divorce costs, after which the game ends. If, instead, the couple decides not to break up, time moves on to period $d=2$.

All periods $d=2,3, \ldots$, are identical to period $d=1$. All agents discount time at rate $r \in[0,1)$. Finally, we assume that the marriage benefit, $B$, is neither so large that all couples find it optimal to marry nor so small that no couple finds it optimal to do so. The timing of the game is summarized in Figure 1.

We now turn to the analysis of this model. A couple marries if and only if each partner prefers marriage to cohabitation. At the beginning of any period $d>0$, the per-partner payoff from cohabitation, $V_{c}$, is implicitly defined by

$$
V_{c}=b+\int_{0}^{r V_{c}} r V_{c} d F(s)+\int_{r V_{c}}^{\infty} s d F(s) .
$$

The first term on the right-hand side is the benefit that each agent realizes by being together with his or her partner. The second term gives the surplus that each partner realizes if the outside option to the relationship is not attractive, namely, when $s \leq r V_{c}$. For such a low realization of $s$, the partners will not break up and thus will still be cohabiting at the beginning of the next period. Finally, the last term gives the expected surplus that each partner realizes if the outside option is attractive, namely, when $s \geq r V_{c}$, so the relationship breaks up.

\footnotetext{
${ }^{9}$ A model in which partners in a couple have different realizations of $b$ and $s$ gives similar results to those presented. We do not develop this extension here because it considerably lengthens the exposition without adding additional insights.

${ }^{10}$ Note that in this model the two partners in any couple are identical in the sense that, for any action that is taken, they always realize the same payoffs. The partners, therefore, always agree on their marital status and the separation decision. We make this assumption, which could be relaxed, solely to ease exposition.
} 


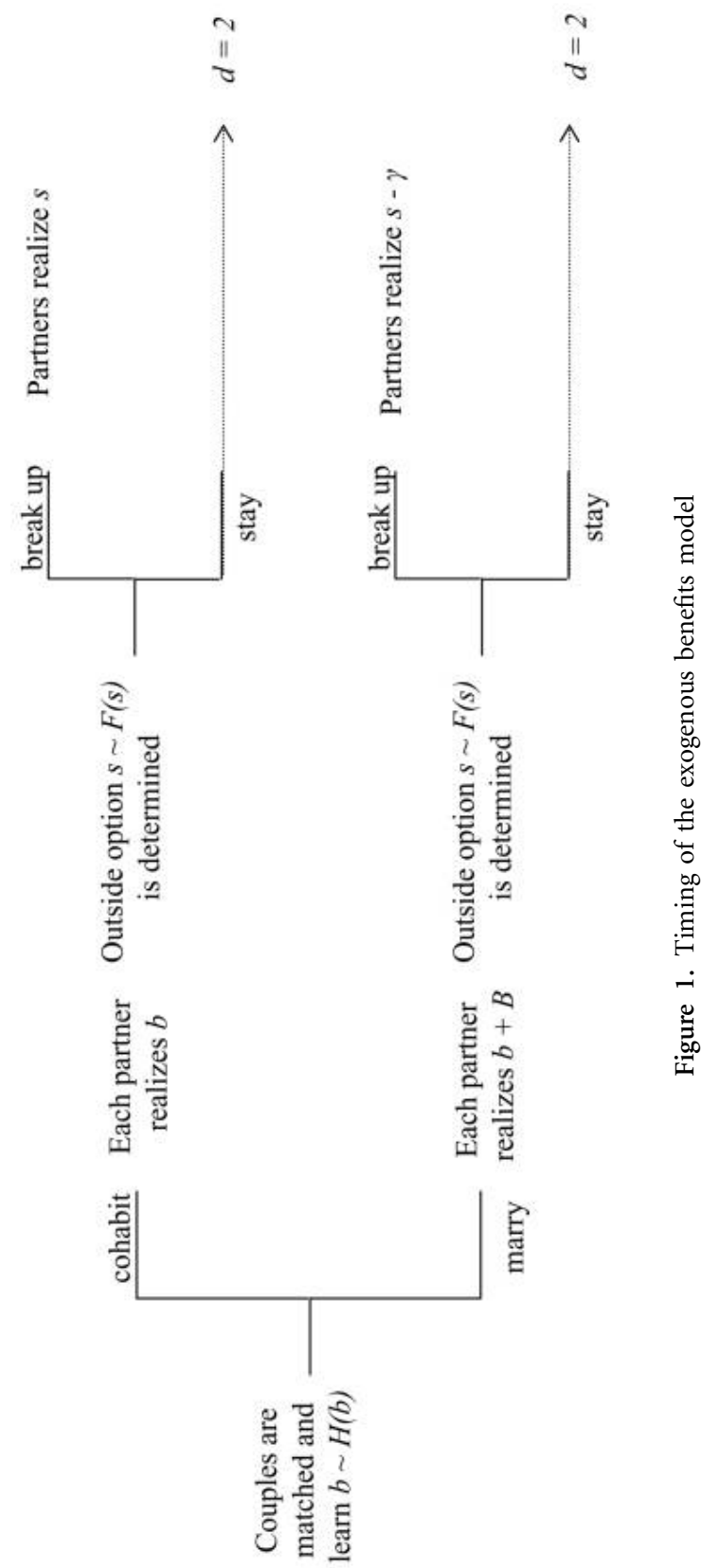


Similarly, at the beginning of any period $d>0$, the per-partner payoff from marriage, $V_{\mathrm{m}}$, is implicitly defined by

$$
V_{\mathrm{m}}=b+B+\int_{0}^{r V_{\mathrm{m}}+\gamma} r V_{\mathrm{m}} d F(s)+\int_{r V_{\mathrm{m}}+\gamma}^{\infty}(s-\gamma) d F(s)
$$

To understand when a couple chooses to marry rather than to cohabit, namely, when $V_{\mathrm{m}} \geq V_{\mathrm{c}}$, we need to compare the benefit of marriage with its cost. In this model, the benefit of marriage is the exogenously given marriage benefit, $B$, and the cost is the higher cost of separation, $\gamma$.

The key observation is that the cost of marriage is decreasing in the match quality of a couple, or $b$. The larger is $b$, the less likely it is that a couple will want to separate in the future, and thus the less likely it is that the additional costs of separation, $\gamma$, will be incurred. In contrast, the benefit of marriage, $B$, is independent of the match quality of a couple, $b$. Intuitively, there then exists a unique cutoff level, $\bar{b}$, that separates couples into those who get married and those who cohabit.

Lemma 1. There exists a unique cutoff level $\bar{b}$ such that couples of match quality $b \geq \bar{b}$ get married and couples of match quality $b<\bar{b}$ cohabit.

We now analyze how a change in divorce costs affects the divorce propensity, which is defined as the proportion of married couples who divorce in year $d$ of their marriage. Consider first a married couple of match quality $b$. At the end of period $d=1$, the partners decide whether to break up and realize $s-\gamma$ or remain in the relationship and realize $r V_{\mathrm{m}}$. Thus, divorce occurs in period $d=1$ if and only if $s-\gamma \geq r V_{\mathrm{m}}$, which occurs with probability $1-F\left(r V_{\mathrm{m}}+\right.$ $\gamma)$. The probability of divorce in the second year of marriage is then $F\left(r V_{\mathrm{m}}+\right.$ $\gamma)\left[1-F\left(r V_{\mathrm{m}}+\gamma\right)\right]$, namely, the probability of not getting divorced in period $d=1$ multiplied by the probability of getting divorced in period $d=2$ conditional on reaching period $d=2$. Thus, for a given married couple, the probability of getting divorced in year $d$ is

$$
p_{d} \equiv F\left(r V_{\mathrm{m}}+\gamma\right)^{d-1}\left(1-F\left(r V_{\mathrm{m}}+\gamma\right)\right) .
$$

We use this expression to calculate the expected divorce propensity for the population as a whole. Recall that matched couples marry if and only if $b \geq \bar{b}$. Thus, the number of marriages is given by $1-H(\bar{b})$. The expected number of couples who get divorced in year $d$ is then given by

$$
P_{d} \equiv \frac{1}{1-H(\bar{b})} \int_{\bar{b}}^{\infty} p_{d} d H(b) .
$$


Consider now the effect of a change in the cost of divorce, $\gamma$, on divorce propensity, $P_{d}$

$$
\frac{d P_{d}}{d \gamma}=\frac{\partial P_{d}}{\partial \gamma}+\frac{\partial P_{d}}{\partial \bar{b}} \frac{\partial \bar{b}}{\partial \gamma} .
$$

The first term on the right-hand side is the incentive effect. It captures the effect of a change in $\gamma$ on $P_{d}$ holding constant the set of people who are married. The second term on the right-hand side is a selection effect. A change in $\gamma$ affects who gets married, and that in turn affects divorce propensity. These two effects are key for our analysis. Before signing them in the next proposition, it is useful to introduce the cumulative divorce propensity, which is defined as the proportion of married couples who divorce in or before year $d$ of their marriage and which is denoted $P_{d}^{\Sigma}=\sum_{t=1}^{d} P_{t}$. The cumulative divorce propensity can be decomposed into a cumulative incentive effect and a cumulative selection effect by replacing $P_{d}$ with $P_{d}^{\Sigma}$ in equation (5). We can now state the first proposition.

Proposition 1: Exogenous Benefit. The selection effect is negative. The incentive effect is negative for small $d$ and positive for large $d$. The cumulative incentive effect is negative.

The intuition for the selection effect is as follows. Since a decline in $\gamma$ reduces the costs of marriage without affecting the benefits, it leads to more couples getting married; that is, $\partial \bar{b} / \partial \gamma$ is positive. The additional couples who get married after the decline in divorce costs are of a lower match quality than those couples who would get married if divorce costs remained high.

Thus, other things being equal, an increase in the number of people who get married-a decline in $\bar{b}$-leads to an increase in divorce propensity at each duration of marriage $d$, so $\partial P_{d} / \partial \bar{b}$ is negative. In short, the model captures the intuition that if couples marry primarily to receive exogenous benefits, then a reduction in the costs of marriage should lead to additional, low-match-quality marriages. These low-quality married couples are more likely than other couples to divorce in the future. Therefore, the selection effect is negative.

The intuition for the incentive effect is as follows. A reduction in divorce costs affects the probability of getting divorced in year $d$ in two opposing ways. On the one hand, such a reduction makes it more likely that a couple gets divorced in period $d$, conditional on not divorcing earlier. On the other hand, however, it also increases the probability that the couple divorces before period $d$. For small $d$, the first effect dominates, and for large $d$, the second effect dominates. For intermediate $d$, whichever effect dominates is ambiguous and, in particular, depends on the distribution of the outside option, $F(s)$. Note, however, that while the sign of the incentive effect depends on the marriage's duration, the cumulative incentive effect, that is, the incentive effect on the propensity to get divorced in or before a given year of marriage, is always negative. Thus, we get the intuitive 
prediction that, holding constant the composition of those who marry, a reduction in divorce costs increases the probability of ever getting divorced.

\subsection{Marriage as a Commitment Device}

We now consider a model in which marriage acts as a commitment device that fosters cooperation in an infinitely repeated Prisoner's Dilemma. For this purpose, we change the previous model in two respects. First, to focus attention on the role of the marriage contract as a commitment device, we abstract from any exogenous benefits from marriage, so that $B=0$. Second, we now assume that a partner realizes the benefit $b$ only if his or her partner cooperates. In particular, at the beginning of any period $d>0$, the partners simultaneously decide whether to cooperate. An agent who cooperates incurs a cost $c$ and generates a benefit $b$ for the partner, while an agent who does not cooperate does not incur any costs or generate any benefits. The remainder of the game is as in the previous model. The timing of the game is summarized in Figure $2 .{ }^{11}$

We now turn to the analysis of the model. Couples of sufficiently high match quality, namely, those for whom $b>c$, face a Prisoner's Dilemma. Their payoffs will be maximized if both partners cooperate, but their short-term interests might induce each partner not to cooperate. We assume that partners play the following trigger strategies: each partner in a couple cooperates in period $d=1$; in every period $d>1$, they cooperate if both partners cooperated in all previous periods, and they do not cooperate if either partner did not cooperate in any previous period.

Consider first the conditions under which cooperation can be sustained by married couples and cohabiting couples. At the beginning of period $d>0$, the value of being in a married relationship in which partners cooperate is

$$
V_{\mathrm{m}}=(b-c)+\int_{0}^{r V_{\mathrm{m}}+\gamma} r V_{\mathrm{m}} d F(s)+\int_{r V_{\mathrm{m}}+\gamma}^{\infty}(s-\gamma) d F(s),
$$

and the value of being in a married but noncooperating relationship is

$$
U_{\mathrm{m}}=\int_{0}^{r U_{\mathrm{m}}+\gamma} r U_{\mathrm{m}} d F(s)+\int_{r U_{\mathrm{m}}+\gamma}^{\infty}(s-\gamma) d F(s) .
$$

The interpretation of these equations is similar to that of equation (1). Given the trigger strategies, a married couple can then sustain cooperation if and only if the deviation payoff $b+U_{\mathrm{m}}$ is less than the nondeviation payoff $V_{\mathrm{m}}$, that is, if and only if

$$
b \leq V_{\mathrm{m}}-U_{\mathrm{m}} .
$$

As in the previous model, the only difference between marriage and cohabitation

${ }^{11}$ This is similar to the model of marital bargaining developed by Lundberg and Pollak (1993). They argue that noncooperation within marriage is an alternative to either cooperation or divorce. 


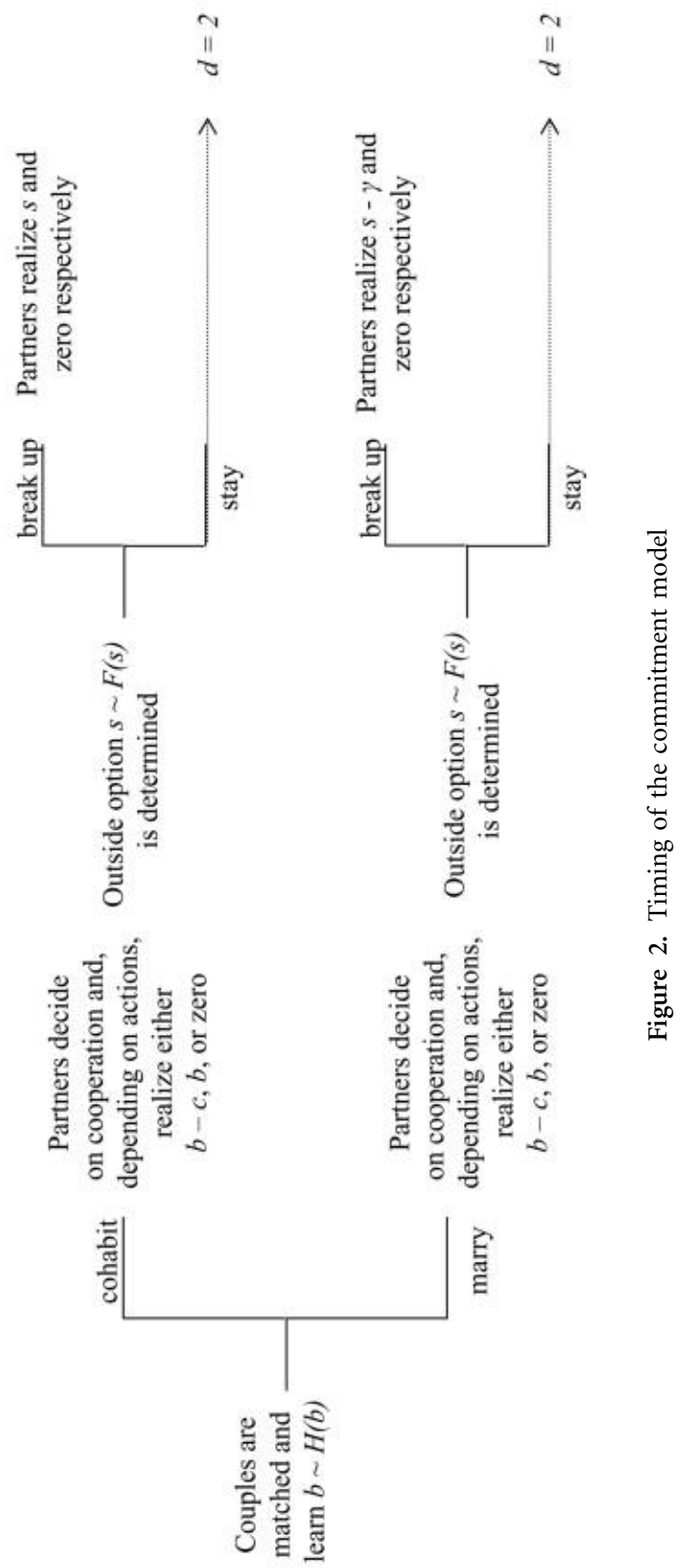


is the existence of divorce costs for married couples. Thus, at the beginning of $d>0$, the value of being in a cohabiting relationship in which partners cooperate is $V_{\mathrm{c}} \equiv V_{\mathrm{m}}(\gamma=0)$, and the value of being in a cohabiting relationship in which partners do not cooperate is $U_{\mathrm{c}} \equiv U_{\mathrm{m}}(\gamma=0)$. We can then state the reneging constraint for cohabiting couples as

$$
b \leq V_{\mathrm{c}}-U_{\mathrm{c}} .
$$

The next lemma establishes that, while both married and cohabiting couples can sustain cooperation as long as their benefit of being together, $b$, is sufficiently large, it can be sustained more easily by married couples.

Lemma 2. There exists a unique $\bar{b}$ and a unique $\underline{b}_{1}<\bar{b}$ such that cooperation can be sustained in a cohabiting relationship if and only if $b \geq \bar{b}$, and it can be sustained in a married relationship if and only if $b \geq \underline{b}_{1}$.

Note that, by reducing the partners' expected outside options, marriage reduces both the cooperation and the punishment payoffs; that is, $V_{\mathrm{m}}<V_{\mathrm{c}}$ and $U_{\mathrm{m}}<$ $U_{c}$. It is, therefore, not immediately obvious that marriage facilitates cooperation. Lemma 2 shows, however, that marriage reduces the cooperation payoff by less than it reduces the punishment payoff, so it does indeed facilitate cooperation.

We can now turn to the main question of which couples marry and which cohabit. Since, conditional on cooperation, cohabitation is preferred to marriage, that is, $V_{\mathrm{c}}>V_{\mathrm{m}}$, and, conditional on noncooperation, cohabitation is also preferred to marriage, that is, $U_{c}>U_{m}$, two necessary conditions for couples to marry are that (i) cooperation cannot be sustained under cohabitation and (ii) cooperation can be sustained under marriage.

Thus, couples of a very low match quality, namely, couples for whom $b<\underline{b}_{1}$, do not marry, and neither do couples of a very high match quality, namely, couples for whom $b>\bar{b}$. Couples of an intermediate match quality can sustain cooperation if and only if they are married. Thus, they marry if and only if they realize a higher payoff if they are married and cooperate than if they cohabit and do not cooperate. Consider, then, the next lemma.

Lemma 3. There exists a unique $\underline{b}_{2}$ such that couples prefer cooperating and being married to not cooperating and cohabiting if and only if $b \geq \underline{b}_{2}$.

The relative sizes of $\underline{b}_{1}$ and $\underline{b}_{2}$ are ambiguous and depend on the parameter values. We can then state the following lemma.

Lemma 4. Couples marry if and only if their match is of intermediate quality, namely, if and only if $b \in[\underline{b}, \bar{b})$, where $\underline{b} \equiv \max \left[\underline{b}_{1}, \underline{b}_{2}\right]$.

In this model, the divorce propensity is then given by

$$
P_{d} \equiv \frac{1}{H(\bar{b})-H(\underline{b})} \int_{\underline{b}}^{\bar{b}} d_{d}(\gamma) d H(b),
$$


where $d_{d}(\gamma)$ is defined in equation (3) and gives the divorce probability for a given couple in year $d$ of their marriage, and $H(\bar{b})-H(\underline{b})$ is the number of marriages.

To see the effect of a decline in divorce costs on divorce propensity, consider first how such a decline affects the number of marriages, $H(\bar{b})-H(\underline{b})$. Changes in divorce costs do not affect $\bar{b}$ since they do not influence the ability of unmarried partners to cooperate. They do, however, affect $\underline{b}$. Recall that $\underline{b}=\max \left[\underline{b}_{1}, \underline{b}_{2}\right]$, where $\underline{b}_{1}$ is the cutoff level of $b$ above which married couples can sustain cooperation and below which they cannot, and $\underline{b}_{2}$ is the cutoff level of $b$ above which couples prefer a cooperating, married relationship to a noncooperating, cohabiting relationship.

A decline in divorce costs, $\gamma$, increases $\underline{b}_{1}$ and decreases $\underline{b}_{2}$. The intuition for the former is that a reduction in divorce costs, $\gamma$, makes it harder to sustain cooperation in a married relationship. Thus, with a lower $\gamma$, only couples of a higher match quality, that is, couples with a higher $b$, can sustain cooperation in a marriage. The intuition for the latter is that a reduction in $\gamma$ makes it even more attractive to be in a married and cooperating relationship than to be in a cohabiting and noncooperating relationship. This is the case since a reduction in divorce costs allows married couples to realize good outside options at a lower cost.

Thus, a decline in divorce costs can lead to more marriages (if $\underline{b}_{2}>\underline{b}_{1}$ ) or fewer marriages (if $\underline{b}_{1}>\underline{b}_{2}$ ). If it leads to more marriages, the average match quality of married couples is reduced, and if it leads to fewer marriages, the average match quality of married couples is increased.

We can now turn to the comparative statics. Consider first the marginal effect of a change in divorce costs, $\gamma$, on divorce propensity,

$$
\frac{d P_{d}}{d \gamma}=\frac{\partial P_{d}}{\partial \gamma}+\frac{\partial P_{d}}{\partial \underline{b}} \frac{\partial \underline{b}}{\partial \gamma} .
$$

As in the previous model, the change in divorce propensity can be decomposed into an incentive effect, the first term on the right-hand side, and a selection effect, the second term on the right-hand side. Also as in the previous model, the cumulative divorce propensity $P_{d}^{\Sigma}=\sum_{t=1}^{d} P_{d}$ can be similarly decomposed by replacing $P_{d}$ with $P_{d}^{\Sigma}$ in equation (11).

Proposition 2: Commitment. The selection effect is negative if $\underline{b}_{2}>\underline{b}_{1}$ and is positive otherwise. The incentive effect is negative for small $d$ and positive for large $d$. The cumulative incentive effect is negative.

The selection effect is negative if a decline in divorce costs leads to more marriages, and since these additional marriages are of relatively low match quality, this situation leads to an increase in divorce propensity at each duration of marriage $d$, so $\partial D_{d}(\gamma, \underline{b}) / \partial \bar{b}$ is negative. In contrast, the selection effect is positive if a decline in divorce costs leads to fewer marriages, and since the couples who 
no longer get married are of relatively low match quality, this situation decreases divorce propensity. The model captures the intuition that a reduction in divorce costs makes marriage a less effective commitment device. As a result, couples of low match quality, who cooperate only if they have access to a strong commitment device, no longer marry. Hence, the selection effect can be positive. The intuition behind the incentive effect and the cumulative incentive effect is as in the previous model.

\subsection{Marriage as a Signaling Device}

We now develop a model in which an individual can use a marriage proposal to signal private information. For this purpose, we change the basic model from Section 3.1 in two regards. First, to focus attention on the role of the marriage contract as a signaling device, we again abstract from any exogenous marriage benefits, so that $B=0$. Second, we change the setup in period $d=0$ so that after a couple has been matched, only the man observes the match quality of the couple, $b$, while the woman knows only that it is randomly drawn from a distribution, $H(b) .^{12}$

After having observed $b$, the man can either break up, propose cohabitation, or propose marriage. In the case of a proposal, the woman can either accept or reject. If she accepts, the couple starts a long-term relationship.

We assume that starting a long-term relationship is costly since partners have to invest in getting to know each other and are less effective in searching for alternative partners. We model these costs in a reduced form by assuming that on acceptance of a man's proposal by the woman, she incurs a cost, denoted $c_{\mathrm{W}}$, and the man incurs a cost, denoted $c_{\mathrm{M}}$. After a proposal is accepted, and the costs of starting a relationship are incurred, time moves on to period $d=1$. If the woman rejects a proposal, or the man does not propose and instead breaks up, the partners realize their randomly drawn outside option, $s \sim F(s)$. The timing of the game is summarized in Figure 3.

The key difference between men and women in this model is the difference in the costs of starting a long-term relationship. If this difference were very small, there would be no need for men to signal their private information by proposing marriage, since women would find it optimal to accept the cohabitation proposal of any man willing to make such a proposal. We therefore assume that $c_{\mathrm{W}}$ is large enough relative to $c_{\mathrm{M}}$ so that women do not want to start a long-term relationship with the average man who prefers cohabitation to being single. ${ }^{13}$

We now turn to the analysis of the model. Upon being matched and learning the realization of $b$, a man must decide whether to break up, propose cohabitation, or propose marriage. The expected payoff in cohabitation is given by equation (1), and the expected payoff in marriage is given by equation (2) for

\footnotetext{
${ }^{12}$ We refer to the informed party as the man only for expositional convenience.

${ }^{13}$ This assumption is stated precisely in Appendix A. The case when this assumption is not satisfied is trivial and economically uninteresting.
} 


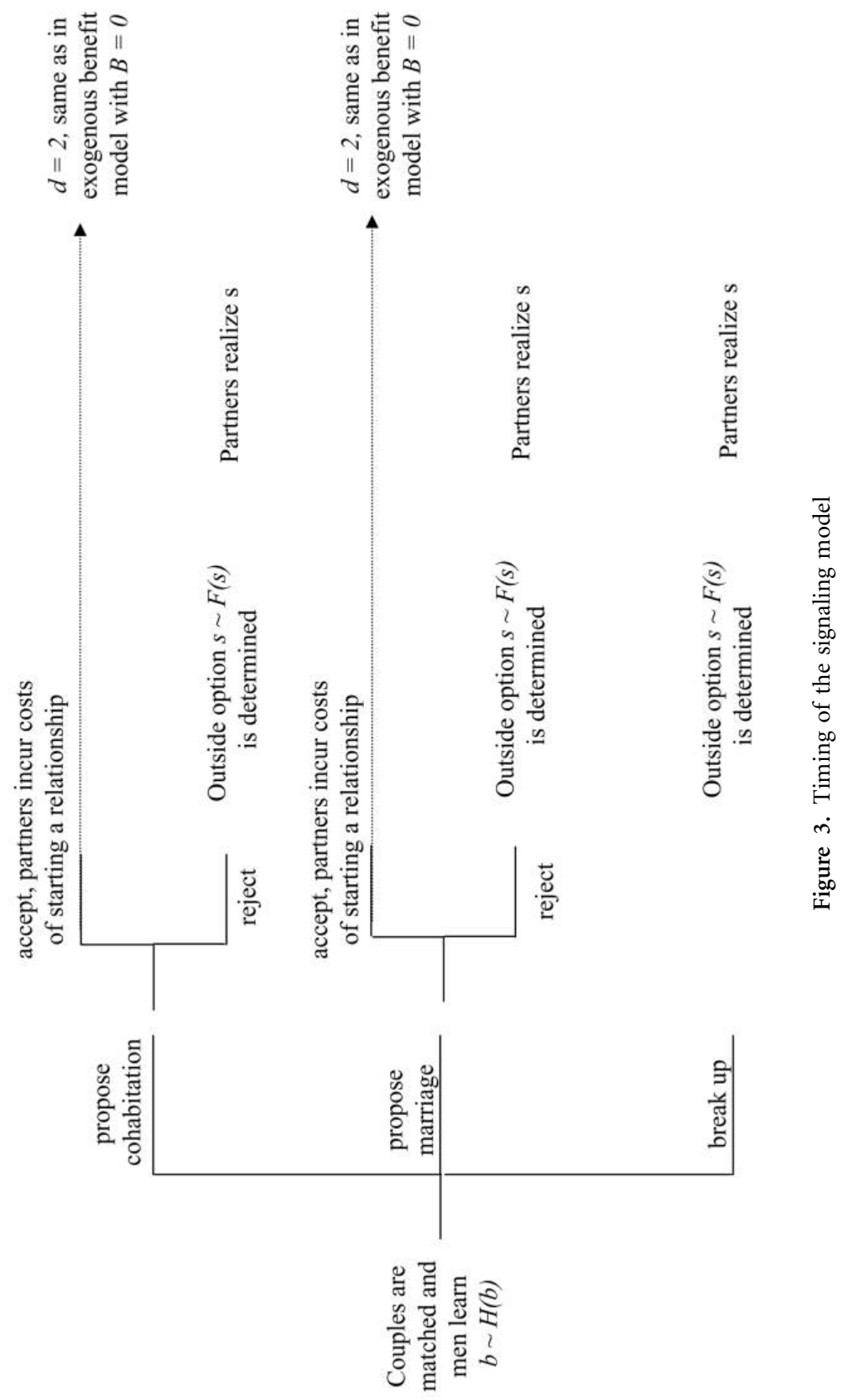


$B=0$. Note that all men prefer cohabitation to marriage, that is, $V_{\mathrm{c}}>V_{\mathrm{m}}$ for all $b$, since marriage increases the costs of separation without generating any direct benefits. Note also that while the expected payoff, $E(s)$, that a man receives when he breaks up is independent of $b$, the expected payoffs of cohabitation and marriage are increasing in $b$. The following lemma follows immediately from these observations.

Lemma 5. There exist two critical values, $\underline{b}$ and $\bar{b}>\underline{b}$, such that a man prefers cohabitation to breaking up if and only if $b \geq \underline{b}$, and he prefers marriage to breaking up if and only if $b \geq \bar{b}$.

As in any signaling model, there exist pooling equilibria. Since those who argue that the marriage contract is used as a signaling device have in mind separating equilibria, we focus on them. ${ }^{14}$

Lemma 6. When the cost of starting a long-term relationship for a woman, $c_{\mathrm{W}}$, is sufficiently low, there exists a separating equilibrium of the following form: any man for whom $b \in[\bar{b}, \infty)$ proposes marriage and his proposal is accepted, and any man for whom $b \in[0, \bar{b})$ breaks up.

In the separating equilibrium, men who learn that the quality of their match is high differentiate themselves from those who learn that their match quality is low by proposing marriage. Women understand that only men with a high $b$ are willing to get married and agree to marriage as long as their cost of starting a long-term relationship is not too high.

We can now analyze the effect of a decline in divorce costs on divorce propensity. Divorce propensity is given by equation (4), where $p_{d}(\gamma)$ is defined in equation (3). As in the previous models, the effect of a change in divorce costs on divorce propensity can be decomposed into an incentive and a selection effect,

$$
\frac{d P_{d}}{d \gamma}=\frac{\partial P_{d}}{\partial \gamma}+\frac{\partial P_{d}}{\partial \bar{b}} \frac{\partial \bar{b}}{\partial \gamma}
$$

Also as in the previous models, the cumulative divorce propensity $P_{d}^{\Sigma}=$ $\sum_{t=1}^{d} P_{d}$ can be similarly decomposed by replacing $P_{d}$ with $P_{d}^{\Sigma}$ in equation (12).

Proposition 3: Signaling. The selection effect is negative. The incentive effect is negative for small $d$ and positive for large $d$. The cumulative incentive effect is negative.

The model captures the intuition that if marriage is used as a signaling device, then a reduction in the cost of using this signal should lead to more agents

\footnotetext{
${ }^{14}$ The condition under which separating equilibria exist in this model is stated explicitly in Appendix A. Intuitively, for separating equilibria to exist, $c_{\mathrm{W}}$ has to be large enough relative to $c_{\mathrm{M}}$.
} 
making use of this signal. ${ }^{15}$ Since these additional agents were not previously willing to send the signal, they must have a lower match quality with their prospective partners than do those agents who were willing to send the signal when its cost was high. The selection effect is then negative, since a decline in the cost of divorce leads to more marriages $(\partial \bar{b} / \partial \gamma>0)$, and because these additional marriages are of relatively low match quality, this situation increases divorce propensity at each duration of marriage $d$, so $\partial p_{d} / \partial \bar{b}$ is negative. The intuition for the incentive and the cumulative incentive effect is as in the previous models.

\subsection{Summary of Theoretical Predictions}

We have formalized three prominent hypotheses on why people enter into marriage contracts. In each model, the comparative static we focus on is the effect of divorce costs on divorce propensity. The analysis highlights that a decline in divorce costs affects divorce propensity through an incentive effect-by changing the probability of divorce for a married couple in a given year of marriageand through a selection effect-by changing the composition of couples who marry.

With regard to the incentive effect, all the models have the intuitive prediction that with lower divorce costs (i) the divorce propensity is higher in the first few years of marriage, so badly matched couples break up earlier, (ii) because more badly matched couples break up earlier, then conditional on the marriage having survived sufficiently long, the divorce propensity is lower in later years, and (iii) the cumulative divorce propensity is higher, independent of the duration of marriage, so the probability of ever divorcing is higher. In short, all the models predict that the incentive effect will be positive in the first few years of marriage and negative in later years and that the cumulative incentive effect is always negative.

With regard to the selection effect, if couples get married primarily because it allows them to realize exogenous benefits, then a reduction in the costs of exiting marriage leads to additional, low-match-quality marriages. Similarly, if marriage serves as a signaling device, then a reduction in the cost of using this signal induces additional, low-match-quality agents to make use of it. Hence, the exogenous benefit and signaling models predict that the selection effect is negative, since a decline in divorce costs induces additional low-match-quality couples to get married, who are then more likely to divorce. In contrast, the commitment model of marriage allows for the possibility that with lower divorce costs, low-match-quality couples no longer get married. This is because with lower divorce costs, the strength of marriage as a commitment device is weakened, and so only couples of a better match quality will want to marry for this purpose. Hence, the selection effect can be positive.

${ }^{15}$ Of course, if the cost of the signal becomes too small, it can no longer be used as a credible signaling device. In other words, separating equilibria do not exist if the cost of divorce is too low. 
The models also make further predictions on the effects of lower divorce costs on marriage and cohabitation rates and on the match quality of marginal married and cohabiting couples. Because of data and space constraints, we leave the use of those additional predictions to discriminate between the models of marriage to future research.

\section{Empirical Analysis}

\subsection{Unilateral Divorce Law}

The 1970s was a period of major reform in American divorce laws, foremost of which was the introduction of unilateral divorce law. Between 1968 and 1977, the majority of states passed such legislation, moving from a fault-based regime in which the dissolution of marriage required the mutual consent of both spouses to one in which either spouse could unilaterally file for divorce and no fault had to be proved. Criticism of the mutual-consent system stemmed from the view that it reduced the welfare of spouses and led to perjured testimony in collusive divorce proceedings that fostered disrespect toward the law. Legislators were also motivated to improve welfare within families and end the legal convention in which extreme cruelty was almost the only universal ground for divorce (Parkman 1992). ${ }^{16}$

As was discussed in Section 2, we follow the claims in the law and economics literature and the opinions of legal practitioners and view unilateral divorce laws as reducing divorce costs. The introduction of unilateral divorce, therefore, corresponds to a one-off and permanent reduction in the costs of exiting marriage, $\gamma$, the effects of which have been discussed in the context of each of the three underlying models of marriage. Table 1 reports the year of adoption of unilateral divorce laws by state. To allow our results to be directly comparable to those in the existing literature, we follow the same coding as in Friedberg (1998, table $1) .^{17}$

\subsection{Data}

We exploit individual marriage and divorce certificate data from the United States for our empirical analysis. These certificates cover all marriages and di-

${ }^{16}$ However, there remain concerns over the potential simultaneity between the adoption of unilateral divorce laws and marriage market outcomes. Our empirical method addresses these concerns directly by controlling for state-specific trends in divorce propensities.

${ }^{17}$ The relevant divorce law applying to an individual is normally that in the state of residence. Although an individual can file for divorce in another state, this right is subject to meeting residency requirements. States require a spouse to be a resident, often for at least 6 months and sometimes for up to 1 year, before being eligible to file for divorce in their jurisdiction. Currently, only three states-Alaska, South Dakota, and Washington-have no statutory requirement for resident status. Furthermore, any legal decision regarding property division, alimony, custody, and child support is not valid unless the nonresident spouse consents to the jurisdiction of the court. If, however, a spouse accepts the jurisdiction of a court in another state, the courts of all U.S. states recognize the divorce settlement. 
Table 1

Divorce Laws and Data Coverage

\begin{tabular}{|c|c|c|}
\hline & $\begin{array}{c}\text { Unilateral } \\
\text { Divorce Law } \\
\text { Introduced }\end{array}$ & $\begin{array}{c}\text { Data from Marriage } \\
\text { and Divorce } \\
\text { Certificates }\end{array}$ \\
\hline Alabama & 1971 & 1968-95 \\
\hline Alaska & 1968 & 1968-95 \\
\hline Arizona & 1973 & \\
\hline \multicolumn{3}{|l|}{ Arkansas } \\
\hline California & 1970 & $1968-77$ \\
\hline Colorado & 1971 & \\
\hline Connecticut & 1973 & $1968-95$ \\
\hline Delaware & & $1981-95$ \\
\hline District of Columbia & & 1986-95 \\
\hline Florida & 1971 & \\
\hline Georgia & 1973 & $1968-95$ \\
\hline Hawaii & 1973 & $1968-95$ \\
\hline Idaho & 1971 & $1968-95$ \\
\hline Illinois & & 1968-95 \\
\hline Indiana & 1973 & \\
\hline Iowa & 1970 & 1968-95 \\
\hline Kansas & 1969 & $1968-95$ \\
\hline Kentucky & 1972 & $1969-95$ \\
\hline \multicolumn{3}{|l|}{ Louisiana } \\
\hline Maine & 1973 & \\
\hline Maryland & & 1968-95 \\
\hline Massachusetts & 1975 & 1979-95 \\
\hline Michigan & 1972 & $1968-95$ \\
\hline Minnesota & 1974 & \\
\hline \multicolumn{3}{|l|}{ Mississippi } \\
\hline Missouri & & $1968-95$ \\
\hline Montana & 1975 & $1968-95$ \\
\hline Nebraska & 1972 & 1968-95 \\
\hline Nevada & 1973 & \\
\hline New Hampshire & 1971 & 1979-95 \\
\hline \multicolumn{3}{|l|}{ New Jersey } \\
\hline New Mexico & 1973 & \\
\hline New York & & 1969-95 \\
\hline \multicolumn{3}{|l|}{ North Carolina } \\
\hline North Dakota & 1971 & \\
\hline Ohio & & $1968-95$ \\
\hline Oklahoma & 1968 & \\
\hline Oregon & 1973 & $1968-95$ \\
\hline Pennsylvania & & $1968-95$ \\
\hline Rhode Island & 1976 & $1968-95$ \\
\hline South Carolina & & 1971-95 \\
\hline South Dakota & 1985 & 1968-95 \\
\hline Tennessee & & 1968-95 \\
\hline Texas & 1974 & \\
\hline Utah & & 1968-95 \\
\hline Vermont & & $1968-95$ \\
\hline Virginia & & $1968-95$ \\
\hline Washington & 1973 & \\
\hline \multicolumn{3}{|l|}{ West Virginia } \\
\hline Wisconsin & & $1968-95$ \\
\hline Wyoming & 1977 & 1968-95 \\
\hline
\end{tabular}

Note. The coding for unilateral divorce follows that in Friedberg (1998, table 1). She uses mostly secondary sources to code unilateral divorce as when divorce requires the consent of only one spouse and is granted on grounds of irretrievable breakdown, irreconcilable differences, and/or incompatibility. Marriage and divorce certificate data were obtained from the National Vital Statistics System of the National Center for Health Statistics. 
vorces in 33 states that have occurred since 1968 and were dissolved through divorce prior to 1995. Therefore, marriages of duration between 0 and 27 years are observed in the data. ${ }^{18}$ The data cover the universe of marriages and divorces in small states and a representative sample in larger states. The certificates include information on the state and year in which the marriage began, the state and year in which the divorce occurred, as well as some demographic characteristics of each partner. Table 1 details the years of coverage by state in the certificate data.

The dependent variable in our analysis is the propensity to divorce among the population of couples in state $s$ who divorce in year $t$ and have been married for $d$ years, which corresponds to $P_{d}$ in the theoretical analysis as defined in equation (4). Empirically this is defined as

$$
p_{d s t}=\frac{\text { number of divorces in state } s \text {, year } t \text {, of duration } d}{1000 \times \text { number of marriages in state } s \text { in year }(t-d)} .
$$

Our working sample contains 12,345 observations of divorce propensities at the duration-state-year level. Of the 33 states covered, 19 adopt unilateral divorce law in some year, and 54.3 percent of the observations are in adopting states when unilateral divorce is in place. ${ }^{19}$

Theory suggests that lower divorce costs have both an incentive and a selection effect on divorce propensity. The incentive effect relates to the number of years the couple has been married under the unilateral divorce regime. Consider the cohort of couples that divorce $d$ years after marriage in state $s$ in year $t$. Suppose further that unilateral divorce was adopted in state $s$ in year $T_{s}$. There are two cases to consider. First, if these couples married after a unilateral divorce law was in place, they have been exposed to lower divorce costs for the duration of their marriage, $d$. Alternatively, if they married before the divorce law was changed, they have been exposed to $t-T_{s}$ years of unilateral divorce. Hence, the number of years these couples have been married under unilateral divorce laws and exposed to the incentive effect of lower divorce costs is

$$
\text { incentive }_{d s t}=\min \left[t-T_{s}, d\right] .
$$

The selection effect relates to the effect of unilateral divorce on the propensity to divorce through its effect on the composition of those who marry. Theoretically, a change in the law may have an immediate effect on the selection into marriage. More realistically, however, it may take time for couples to learn about the magnitude and permanence of changes in divorce costs. Hence, for any cohort of divorcing couples, the selection effect relates to the number of years

\footnotetext{
${ }^{18}$ We define a marriage to have a duration of 0 years if it lasts less than 12 months.

${ }^{19}$ The average marital duration is 9.23 years, the average year of marriage is 1977 , and the average year of divorce is 1986 . These figures do not significantly differ between adopting and nonadopting states. The next section provides a complete set of descriptive evidence.
} 
prior to the year of marriage, if any, that unilateral divorce laws were in place and is therefore given by

$$
\text { selection }_{d s t}=\max \left[t-d-T_{s}, 0\right] .
$$

Within a state-year, the incentive and selection effects vary across cohorts of different marital durations. It is, therefore, possible to identify the incentive and selection effects separately from state-year-specific factors that determine divorce propensities. This is an important part of our identification strategy that we will later discuss in more detail. In addition, taking the theoretical framework literally, we also show that our main results are robust to using a simpler dummy variable for the selection effect. This dummy selection effect is therefore set equal to one if selection ${ }_{d s t}>0$ and is zero otherwise.

\subsection{Descriptives}

Table 2 provides descriptive evidence on the years couples have been married under unilateral divorce laws, which corresponds to the incentive effect, and the number of years prior to the year of marriage that unilateral divorce laws were in place, which corresponds to the selection effect. We also show the overall variation in the incentive $e_{d s t}$ and selection ${ }_{d s t}$ variables defined in equations (14) and (15) and decompose each into the variation that arises between marriages of the same duration that end in divorce in different state-years and the variation we exploit across marriages of different durations within each state-year.

The data in Table 2 show that among all states, the average married couple has lived under unilateral divorce laws for 4.62 years, and this rises to 8.08 years among adopting states. Within these states, there is considerable variation in incentive $_{d s t}$ between cohorts divorcing in different state-years. Importantly for our analysis, variations in incentive ${ }_{d s t}$ remain among divorcing couples within the same state and year.

The data in columns 3 and 4 split couples in adopting states into those married before the introduction of unilateral divorce (and so have 0 years of selection by definition) and those married after the introduction of unilateral divorce. These data show that the incentive effect of lower divorce costs is identified from those couples in adopting states married before the introduction of unilateral divorce. This is because, among couples married after a unilateral divorce law is in place, incentive $e_{d s t}$ always corresponds to the year of divorce minus the year unilateral divorce was introduced, $t-T_{s}$.

The data in Table 2 also show that among all states, the average marriage formed 3.03 years after the introduction of unilateral divorce. This rises to 5.30 years among adopting states and rises further to 8.33 years when we consider the subsample of marriages in adopting states that formed after the introduction of unilateral divorce. In each subsample, there is greater variation in selection $n_{d s t}$ among marriages of different durations within the same state-year than between couples with different marital durations. 


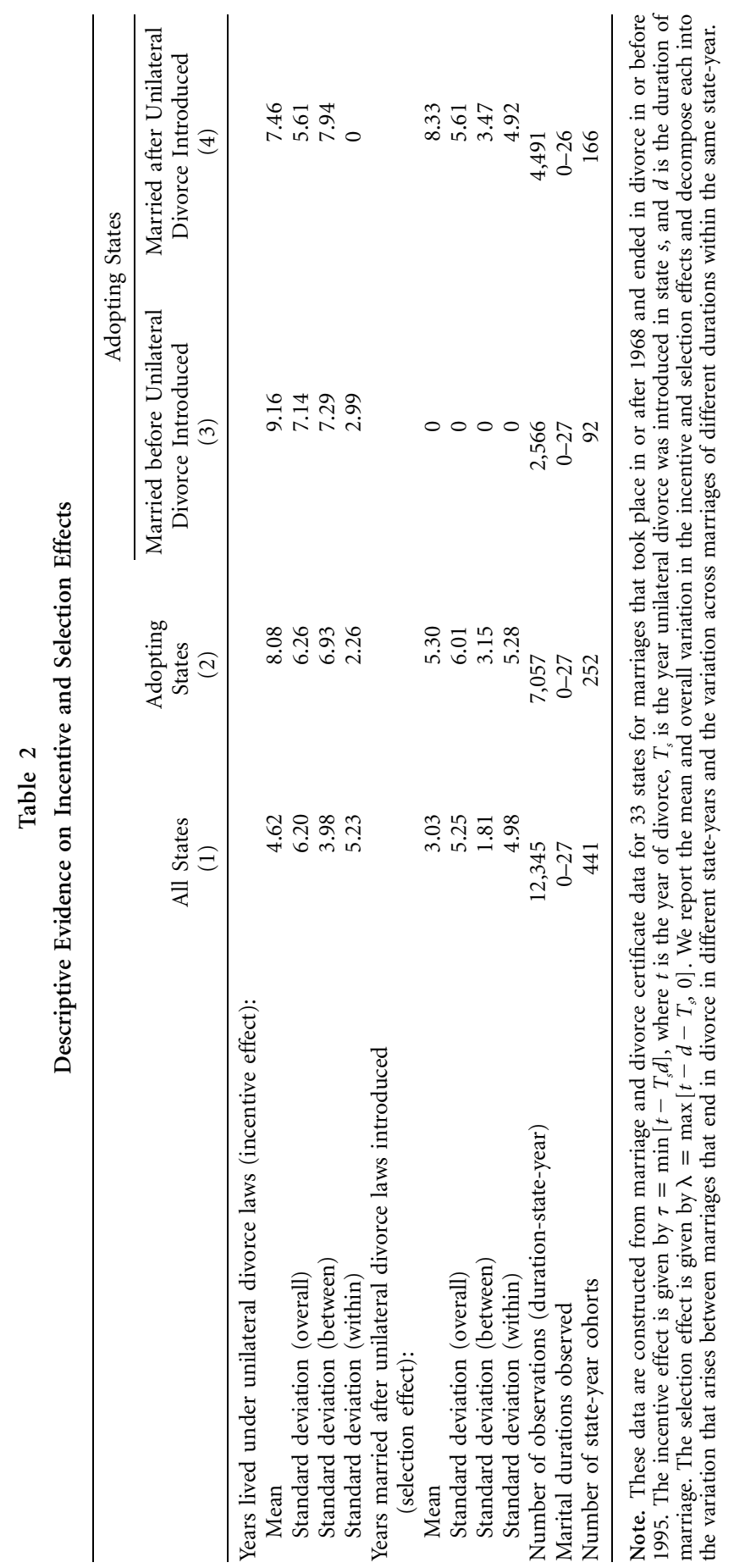




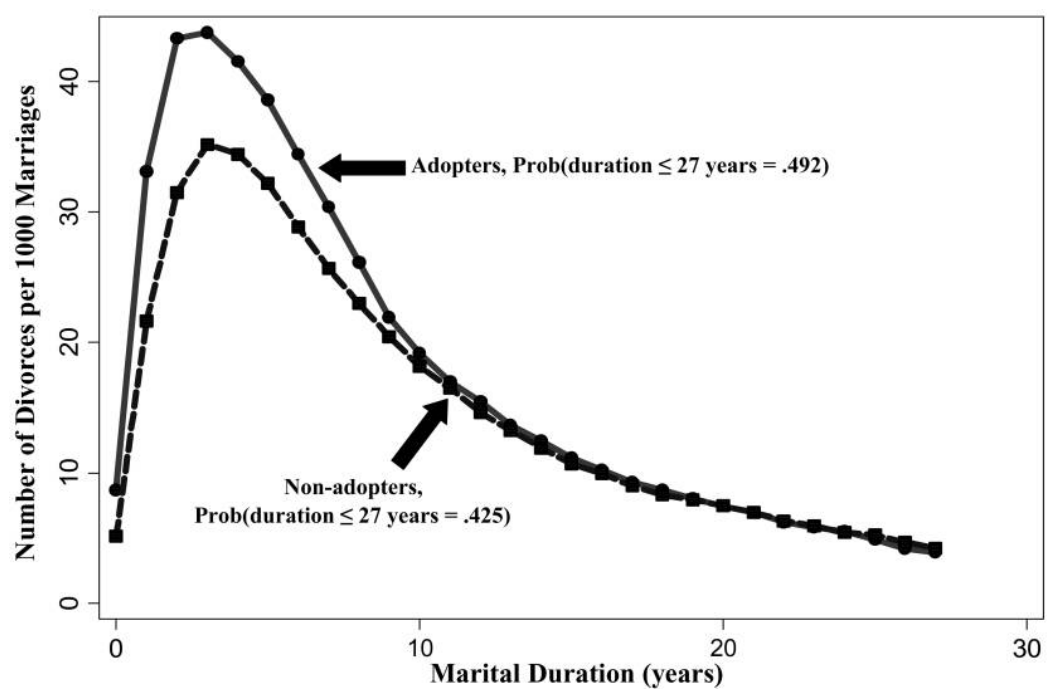

Figure 4. Divorce hazards by adoption of unilateral divorce

Table 2 also reveals the data dimensions in each of these subsamples. The incentive (selection) effect is identified from 2,566 $(4,491)$ observations in 92 (166) state-year of divorce cohorts in adopting states, corresponding to 36.4 percent (63.6 percent) of all observations from adopting states.

We provide descriptive evidence on the incentive and selection effects of unilateral divorce by comparing divorce propensities between adopting and nonadopting states; in adopting states, between couples married before the introduction of unilateral divorce and those married after; and in adopting states, between couples married between 1 and 4 years after the introduction of unilateral divorce and those married at least 5 years after its introduction.

Figure 4 graphs the divorce propensity by marital duration for adopting and nonadopting states. Divorce propensity at each marital duration is higher in adopting states. The unconditional probability of divorcing in the first 27 years of marriage is .492 in adopting states-almost one in two marriages end in divorce in these states. The probability is lower in nonadopting states. Differences in these divorce propensities may reflect permanent differences between adopting and nonadopting states, including those unrelated to unilateral divorce laws. We address this empirically by allowing the divorce propensity to differ across adopting and nonadopting states at each marital duration. We also present all of our results after exploiting only the variation in divorce propensities within adopting states.

Figure 5 shows divorce propensities for those in adopting states who were married before the introduction of unilateral divorce versus those who were 


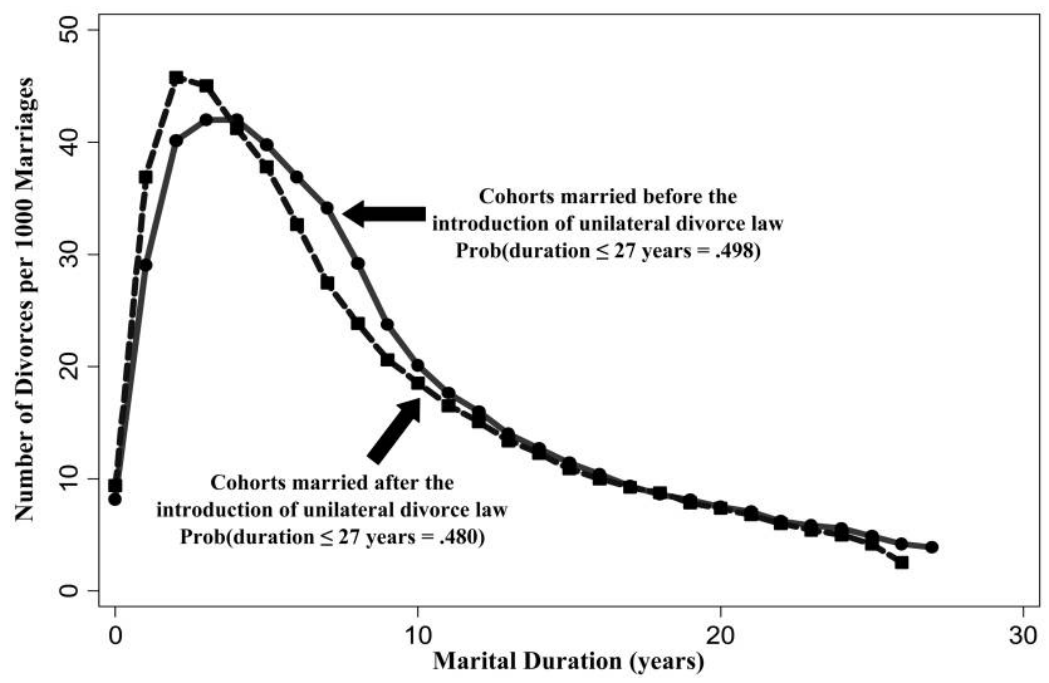

Figure 5. Divorce hazards by year of marriage in adopting states

married after its introduction. Divorce propensities among the former group reflect only an incentive effect, while among the latter group they reflect both incentive and selection effects. Figure 5 shows that those married after unilateral divorce was in place are more likely to divorce in the first 4 years of marriage but are less likely to divorce subsequently than are couples who married before unilateral divorce was in place.

Two points are of note. First, these differences in the divorce propensities by marital duration are in line with the incentive effect of lower divorce costs predicted by all the theories of marriage. Namely, as divorce costs fall, the divorce propensity rises in early years of marriage and falls in later years. Second, theory suggests that the cumulative incentive effect should be negative-holding selection constant, the probability of ever divorcing should increase as divorce costs fall. However, the data plotted in Figure 5 imply that the unconditional probability of divorcing in the first 27 years of marriage is .498 for those married before the introduction of unilateral divorce (and so have 0 years of selection) and is actually slightly lower for those married after the introduction of unilateral divorce (and so have positive years of selection). This finding suggests that the overall probability of ever divorcing falls for the second group because the selection effect of lower divorce costs reduces the propensity to divorce. In other words, this evidence hints at a positive selection effect that can be reconciled with theory if couples predominantly use marriage as a commitment device.

To more closely isolate the selection effect, Figure 6 shows divorce propensities among couples who got married between 1 and 4 years after the introduction of unilateral divorce and among couples who got married at least 5 years after 


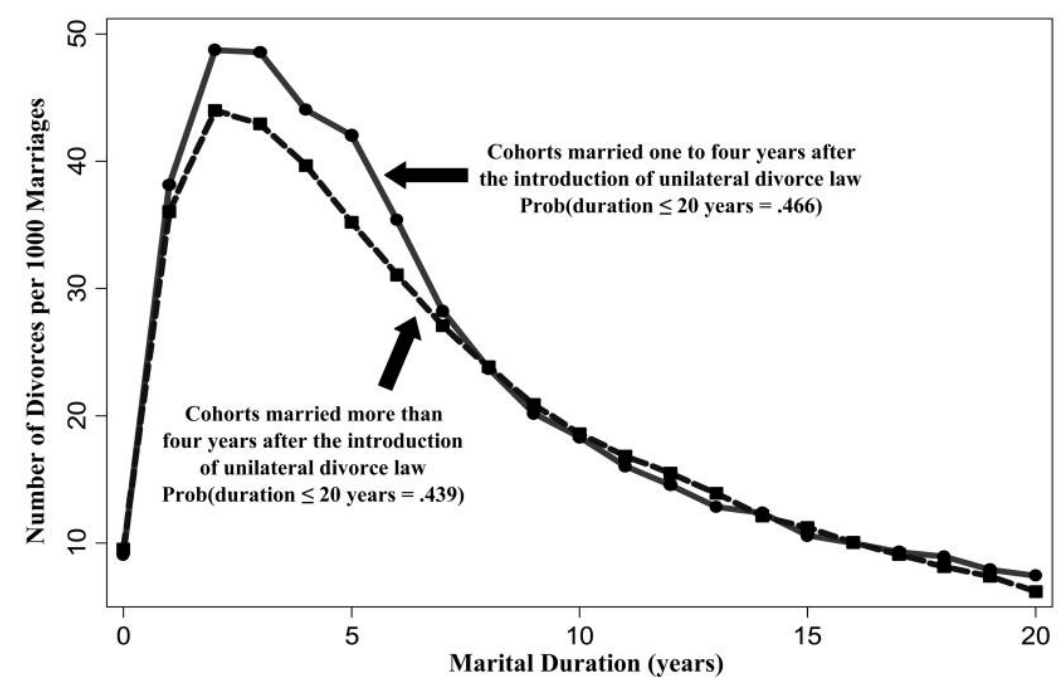

Figure 6. Divorce hazards by years of selection in adopting states

its introduction. While both types of couple experience the same incentive effect during marriage, they obviously differ in the number of years prior to their marriage that lower divorce costs have been in place. We expect divorce propensity to differ between these couples if it takes time for individuals in the marriage market to learn the extent of the decline in divorce costs and change their behavior accordingly. Figure 6 shows that the propensity to divorce is lower for those couples with more years of selection. The unconditional probability of divorcing in the first 20 years of marriage is .466 for those couples with 1-4 years of selection, and it is .439 for those with at least 5 years of selection. ${ }^{20}$ This finding again hints at a positive selection effect.

\subsection{Empirical Method}

We first estimate the effect on the divorce propensity of unilateral divorce law being in place per se. This is a natural benchmark to consider and enables our analysis to be compared to those in the existing literature. We estimate the panel data specification

$$
p_{d s t}=\delta_{d}+\alpha_{s}+\gamma_{t}+\sum_{d} \phi_{d}\left(\delta_{d} \times \text { adopt }_{s}\right)+\beta \text { unilateral }_{s t}+u_{d s t}
$$

where $\delta_{d}, \alpha_{s}$, and $\gamma_{t}$ correspond to duration, state, and year of divorce fixed

${ }^{20}$ We consider marital durations of up to 20 years because for couples with more than 5 years of selection, there is a lower likelihood of observing longer marital durations in the data, which include divorces up to 1995. 
effects, respectively. The estimated $\delta_{d}$ coefficients measure the underlying divorce propensity at each marital duration. These may capture the rate at which individuals learn the true costs and benefits of marriage, for example. The pattern of these divorce propensities is not parametrically restricted. State fixed effects capture permanent differences in the level of divorce propensities across states. For example, the social stigma associated with divorce may differ permanently across states. The year of divorce fixed effects captures changes in divorce propensities over time that are common to all states and marriages within a given year. For example, there may be macroeconomic changes or federal policies that alter the costs and benefits of marriage for all marriages.

One concern, highlighted in Figure 4, is that the propensity to divorce at a given marital duration $d$ systematically differs across states. To address this concern, we control for a series of interactions between each duration fixed effect and a dummy variable, adopt ${ }_{s}$, which is set equal to one if state $s$ ever introduces unilateral divorce and is zero otherwise. Doing this captures in a flexible and nonparametric way any permanent differences in divorce propensities by marital duration between nonadopting and adopting states.

The dummy variable unilateral $l_{s t}$ is set equal to one if a unilateral divorce law is in place in state $s$ in year $t$ and is zero otherwise. The coefficient of interest in the baseline specification in equation (16) is $\beta$, which estimates the effect of lower divorce costs associated with unilateral divorce on the propensity to divorce. This estimate captures both the incentive and the selection effects of lower divorce costs. The implied change in the probability of divorcing in or before year $d$ is then $\Sigma_{d} \hat{\beta}=d \hat{\beta}$, which is related to $d P_{d}^{\Sigma} / d \gamma$ in the theoretical analysis.

The error term $u_{d s t}$ captures unobserved duration-state-year-specific determinants of divorce propensity. The propensity to divorce after $d$ years of marriage in state $s$ may not be independent over time. Following Bertrand, Duflo, and Mullainathan (2005), we address this concern by allowing the error terms to be clustered by duration-state throughout.

There are two key differences between our approach and that in the previous empirical literature. First, the existing literature typically estimates the effect of unilateral divorce being in place in state-year st on the aggregate divorce rate at the state-year level. An econometric concern with this approach is the presence of unobserved state-year factors that simultaneously determine both the adoption of unilateral divorce and aggregate divorce rates. Examples of such unobservables include social attitudes, labor market outcomes, or political preferences. Alternatively, states with higher rates of divorce or higher rates of growth in divorce rates may be more likely than other states to adopt unilateral divorce laws. Such reverse causality between marriage market outcomes and the adoption of unilateral divorce laws implies that $\hat{\beta}$ is likely to be biased upward.

We address these concerns by exploiting the disaggregated nature of our data. In particular, we additionally control for state-year fixed effects in equation (16). Allowing for such state-specific time trends in divorce propensities differences out within-state changes over time in social attitudes, labor markets, and political 
preferences that may drive the adoption of unilateral divorce laws and divorce propensities.

The second difference between our approach and that in the existing literature is that we exploit the theoretical insight that lower divorce costs affect divorce propensities through an incentive effect and a selection effect. Hence, our preferred specification is

$$
\begin{aligned}
p_{d s t}= & \delta_{d}+\alpha_{s}+\sum_{d} \phi_{d}\left(\delta_{d} \times \text { adopt }_{s}\right)+\beta_{1} \text { incentive }_{d s t} \\
& +\beta_{2} \text { selection }_{d s t}+v_{s t}+u_{d s t}
\end{aligned}
$$

where $v_{s t}$ is a state-year fixed effect. This difference-in-difference-in-difference specification exploits only the variation in divorce propensities across marriages of different durations within a state-year to identify the incentive and selection effects of lower divorce costs. ${ }^{21}$

Theory informs us of the expected signs of the two parameters of interest: $\beta_{1}$, which estimates the incentive effect related to $\partial P_{d} / \partial \gamma$ in the theoretical analysis, and $\beta_{2}$, which estimates the selection effect related to $\left(\partial P_{d} / \partial b\right)(\partial b / \partial \gamma)$ in the theoretical analysis.

With regard to the selection effect, if couples get married primarily because it allows them to realize exogenous benefits, or if marriage serves as a signaling device, then a reduction in the costs of exiting marriage leads to additional, lowmatch-quality marriages. In these cases, the selection effect is negative, since a decline in divorce costs induces additional low-match-quality couples to get married, who are then more likely to divorce. Hence, $\beta_{2}>0$ if either of these hypotheses is true.

In contrast, the commitment model of marriage allows for the possibility that with lower divorce costs, low-match-quality couples no longer get married. This is because with lower divorce costs, the strength of marriage as a commitment device is weakened, and so only couples with a better match quality will want to marry for this purpose. Hence, the selection effect can be positive. Therefore, $\beta_{2}<0$ if this theory accurately describes individual behavior in the marriage market. $^{22}$

With regard to the incentive effect, all the models developed predict that the incentive effect of lower divorce costs is to increase the divorce propensity in the first few years lived under lower divorce costs and to lower it in later years. In specification (17), the incentive effect of lower divorce costs $\beta_{1}$ is constrained

\footnotetext{
${ }^{21}$ With a full set of state-year dummies, the effect of unilateral divorce laws itself cannot be identified. Note also that our dependent variable-divorce propensity-is measured relative to the at-risk population of married couples. In contrast, the existing literature has focused on the number of divorces per 1,000 (adult) population.

${ }^{22}$ If individuals anticipate decreases in divorce costs, there would be changes in the composition of those who marry under mutual-consent divorce laws. This situation biases any estimated selection effect toward zero. We later present evidence that sheds light on whether individuals appear to anticipate decreases in divorce costs.
} 
to be the same across all marriages and, therefore, measures the average incentive effect. We relax this restriction in Section 5.3, as theory suggests should be done.

Finally, all the models predict that the cumulative incentive effect should be negative so that, holding selection constant, a reduction in divorce costs leads to an increase in the probability of ever divorcing. However, note that in equation (17), any change in the divorce propensity that is common to all marriages in the same state-year is actually differenced out. Hence, we cannot use this specification to estimate the probability of ever divorcing. In order to present some evidence on this specific theoretical prediction, we therefore estimate the following specification:

$$
\begin{aligned}
p_{d s t}= & \delta_{d}+\alpha_{s}+\sum_{d} \phi_{d}\left(\delta_{d} \times \text { adopt }_{s}\right)+\beta \text { unilateral }_{s t} \\
& +\beta_{1} \text { incentive }_{d s t}+\beta_{2} \text { selection }_{d s t}+u_{d s t}
\end{aligned}
$$

where the estimated cumulative incentive effect is given by $\sum_{d}\left(\hat{\beta}+\hat{\beta}_{1}\right)=$ $d\left(\hat{\beta}+\hat{\beta}_{1}\right)$. This specification is likely to provide an upper bound on this effect given potential concerns that states in which divorce propensities are higher are more likely than other states to adopt unilateral divorce. These concerns are mitigated within our preferred specification (17), which we use to provide the main estimates of the incentive and selection effects.

We also check the robustness of our results to some assumptions underlying our identification strategy. First, exploiting the variation in divorce propensities in both adopting and nonadopting states is valid only if nonadopting states provide a true counterfactual situation to what would have occurred to trends in divorce propensities in adopting states in the absence of unilateral divorce laws. While we allow the divorce propensity to vary by duration differentially between adopting and nonadopting states, this situation may not be sufficiently flexible to capture all the differences between these states. ${ }^{23}$ We therefore present all of our results in two contexts-first, using all states and, second, exploiting only the variation in divorce propensities within adopting states.

A second identifying assumption is that couples do not change locations in order to marry and divorce in states on the basis of their divorce laws. To assess whether this assumption is valid, we use the fact that between 1972 and 1988 divorce certificates record both the state in which the marriage began and the state in which the divorce occurred. In adopting states, 66 percent of divorces occur in the same state where the marriage began. In nonadopting states, the percentage is actually slightly higher- 73 percent of divorces occur in the same state where the marriage began. There are also no discernible changes over time in these data, in either adopting or nonadopting states. This finding suggests

\footnotetext{
${ }^{23}$ For example, suppose individuals can devote some costly effort to learn the true benefits of their marriages. They may have different incentives to do this as the cost of divorce changes, and this situation introduces systematic differences in divorce propensities between adopting and nonadopting states that may vary by marital duration.
} 
that those who marry in mutual-consent states are not then more likely to want to divorce in unilateral divorce states. ${ }^{24}$

Finally, in order to benchmark our results against those in the existing literature, we have coded the timing of the introduction of unilateral divorce laws as in Friedberg (1998, table 1). However, there remains debate over the precise definition of these moves to unilateral divorce (for a thorough discussion, see Zelder 1993). Following Wolfers (2006), we therefore consider the following alternative codings of unilateral divorce laws: (i) Gruber (2004) codes unilateral divorce laws with no separation requirements, using both primary and secondary sources; (ii) Ellman and Lohr (1998) code when each state adopted either irretrievable breakdown or incompatibility as grounds for divorce. In each recoding of a unilateral divorce law, the estimated incentive and selection effects remain of the same sign, of the same significance, and of comparable magnitudes to those reported in Section $5 .^{25}$

\section{Results}

The empirical analysis proceeds in three stages. Section 5.1 estimates specifications (equations [16]-[18]). Section 5.2 shows how the incentive and selection effects vary across couples within the same state. Section 5.3 sheds light on whether the incentive and selection effects are heterogeneous across states depending on the states' social and economic characteristics.

\subsection{Baseline Estimates}

Table 3 presents our baseline estimates. We first estimate equation (16) to shed light on the effect of lower divorce costs, as measured by the presence of unilateral divorce, on divorce propensities. ${ }^{26}$ The data in column 1 show that after the introduction of unilateral divorce, the propensity to divorce at any given marital duration increases by 4.08 divorces per 1,000 marriages and that this increase is significantly different from zero. The average divorce propensity across all marriages is 22.1. Hence, the implied effect of unilateral divorce is to increase divorce propensity, averaged across marriages of all durations, by 18.5 percent. As a point of comparison, we note that Friedberg (1998) estimates that unilateral divorce laws increase the aggregate divorce rate, measured as the number of divorces per 1,000 population, by 17 percent.

For the data in column 2, we additionally control for the number of years that couples have been married under unilateral divorce laws and have therefore been exposed to the incentive effect of lower divorce costs, as defined in equation

\footnotetext{
${ }^{24}$ Of course, measurement error remains in the dependent variable owing to individuals migrating across states during marriage for reasons that are independent of the divorce laws in place. This biases the estimated standard errors upward.

${ }^{25}$ In order to save space, these results are not presented here but are available on request.

${ }^{26}$ Conditioning only on duration fixed effects in equation (16) explains 66 percent of the variation in divorce propensities. Conditioning only on state fixed effects explains 13 percent, and conditioning only on year fixed effects explains 9 percent.
} 


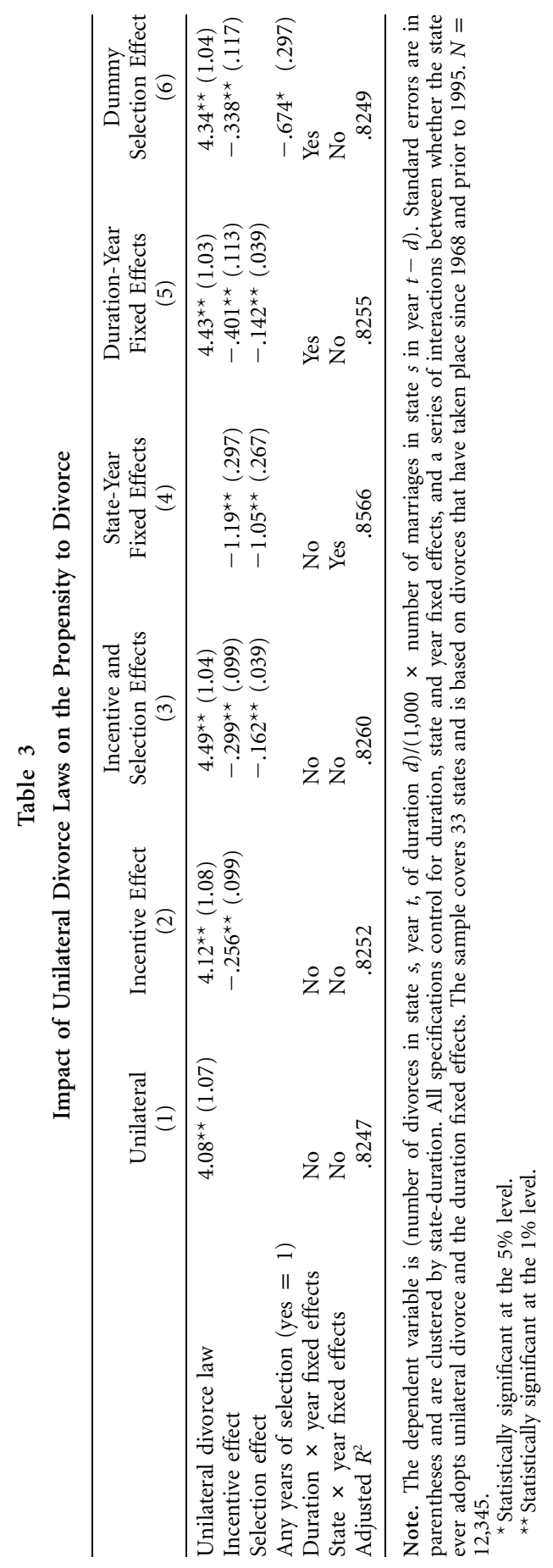


(14). The results imply that as married couples live an additional year under lower divorce costs, the propensity to divorce falls by .256 per 1,000 marriages. This finding is in line with those of Wolfers (2006), who found that the effects of lower divorce costs diminish over time.

Two further points are of note. First, each of the theories of marriage developed earlier suggests that the incentive effect ought to increase divorce propensity in the early years of marriage and reduce it in later years. The results imply that the divorce propensity is indeed higher for those exposed to unilateral divorce laws for $4.08 / .256 \simeq 16$ years of marriage, and it is lower for those who have been married under unilateral divorce laws for longer. Second, all the theories suggest that the cumulative incentive effect is positive at any marital duration. These results imply that the cumulative incentive effect is $27 \times(4.08-$ $.256)=103.2$, so the probability of divorce during the first 27 years of marriage increases when unilateral divorce laws are in place. Relative to a baseline probability of divorce during the first 27 years of marriage in adopting states of .492 (Figure 4), this corresponds to a 21 percent increase.

For the data in column 3, we additionally control for the number of years prior to the year of marriage, if any, that unilateral divorce laws were in place, as defined in equation (15). Doing this captures the selection effect of unilateral divorce-that operates through its effect on the composition of those who marry - on the propensity to divorce. We find that, conditional on the years of marriage actually lived under unilateral divorce laws, this selection effect significantly reduces the propensity to divorce. ${ }^{27}$

We can map this result back to the models of marriage. While we certainly expect each model to capture some element of marriage market behavior, our evidence suggests that the dominant reason why a couple enters into a marriage contract is that it serves as a commitment device. In such a framework, there is a possibility that with lower divorce costs, low-match-quality couples no longer get married, and only couples of a better match quality still prefer to marry. This situation reduces the divorce propensity in steady state. In contrast, if couples get married primarily because it allows them to realize exogenous benefits, or if marriage serves as a signaling device, then a reduction in divorce costs leads to additional, low-match-quality marriages. If these were the dominant reasons why couples enter into marriage contracts, the selection effect should increase the divorce propensity.

For the data in column 4, we then estimate the specification in equation (17), which controls for a complete set of state-year interactions. The results show that within a state-year, couples who have been living under a regime with lower divorce costs for more years have significantly lower divorce propensities. Similarly, couples who were married more years after unilateral divorce laws were

\footnotetext{
${ }^{27}$ The variables incentive ${ }_{d s t}$ and selection ${ }_{d s t}$ are not strongly correlated. Their correlation coefficient is .096 in the entire sample and -.342 among adopting states. A comparison of the data in columns 2 and 3 reveals that once the selection effect is conditioned on, the incentive effect of having lived under a regime with lower divorce costs increases in absolute magnitude slightly.
} 
first introduced in a state are significantly less likely to divorce. In other words, the selection effect of lower divorce costs is also to reduce divorce propensities. The sign of this selection effect implies that the first-order purpose of the marital contract is to serve as a commitment device. ${ }^{28}$

The next specification addresses the concern that there are unobserved determinants of divorce propensities that are common to marriages of the same duration across all states and in the same year. We therefore condition on a full set of duration-year fixed effects instead of the state-year fixed effects. In light of the large changes in divorce hazards through the sample, it may be especially important to control for such interactions. We then exploit the variation in divorce propensities across marriages in different states but of the same duration and year of divorce to identify the incentive and selection effects. The direct effect of the presence of a unilateral divorce law in state $s$ and year $t$ can also then be estimated. The results in column 5 show that the incentive and selection effects continue to be negative and significant.

The next specification uses an alternative definition for the selection effect. If we take the theoretical models literally, there ought to be a differential effect on divorce propensities for couples married before and after the change to unilateral divorce laws. For the data in column 6, we therefore define the selection variable using a dummy variable that is set equal to one if selection ${ }_{d s t}>0$ and is zero otherwise. The results show that this cruder specification of the selection effect leaves the results qualitatively unchanged. ${ }^{29}$

Taken together, the evidence suggests that lower divorce costs reduce divorce propensities through two channels-an incentive effect of having lived under unilateral divorce laws during marriage and a selection effect of having married years after the introduction of unilateral divorce. In relation to the underlying models of marriage, the sign of this selection effect implies that the underlying dominant purpose of the marital contract is to serve as a commitment device.

These results help explain some of the earlier findings in the literature that estimated the effect of unilateral divorce laws on the aggregate divorce rate. For example, both Gruber (2004) and Wolfers (2006) find that the effects of unilateral divorce on aggregate divorce rates disappear around a decade after its intro-

\footnotetext{
${ }^{28}$ The magnitude of the effects, which are shown in column 4 , are also larger than those in the previous specifications. This finding suggests that there exist unobserved factors at the state-year level that increase (decrease) divorce propensities and that are negatively (positively) correlated with the incentive and selection effects. As was recognized in the literature, the presence of such unobservables is also likely to lead the previously estimated effect of unilateral divorce law, $\hat{\beta}$, to be inconsistent. We also used information from the certificate data to control for the average age at marriage of women in the cohort of couples divorcing in year $d$ of marriage who married in state $s$ in year $t$. With such an additional control, the magnitudes and significance of the incentive and selection effects remain similar to those shown in column 4. Cohorts of couples in which women married at an older age have lower divorce propensities, although this effect is not significant at conventional levels.

${ }^{29}$ The results in Table 3 are also largely robust to two further types of robustness check-allowing the error terms to be clustered at the state-year level and estimating the effects by exploiting only the variation within adopting states.
} 
duction. Here we determine precisely why this is so: namely, because the marriage contract serves primarily as a commitment device. When the costs of exiting marriage fall, only higher-match-quality couples are willing to marry. This situation reduces the divorce rate in the long run, as these better-matched couples form a greater share of all married couples in steady state.

Moreover, our theoretical and empirical results are complementary to those in Rasul (2005) on the impact of unilateral divorce laws on marriage rates. Using state-level panel data from 1960 to 2000, Rasul provides evidence that after the adoption of unilateral divorce, marriage rates-measured either as the number of marriages per 1,000 adult population or relative to the population of unmarried individuals_fell significantly and permanently in adopting states, which is consistent with a positive selection effect.

\subsection{Dynamic Effects}

In the baseline specification (17), the parameters of interest, $\beta_{1}$ and $\beta_{2}$, correspond to the incentive and selection effects, respectively, averaged over all marriages. Theory suggests that the selection effect is either always positive or always negative, depending on the underlying reason why couples enter into marriage contracts. However, all the theories developed provide a more precise prediction for how the incentive effect varies with the number of years lived under a regime of lower divorce costs. In particular, the incentive effect of lower divorce costs ought to increase the propensity to divorce in the first few years after they are in place and reduce it in later years. To provide more direct evidence that at least one of the theories developed can explain the patterns of divorce propensities, we explore how the sign and magnitude of the incentive effect varies by the number of years lived under unilateral divorce laws.

We modify the specification used for the data presented in column 4 of Table 3 to allow the incentive effect of lower divorce costs to vary by the years lived under unilateral divorce laws, conditional on a full set of state-year fixed effects. We therefore estimate the following panel data specification:

$$
\begin{aligned}
p_{d s t}= & \delta_{d}+\alpha_{s}+\sum_{d} \phi_{d}\left(\delta_{d} \times \text { adopt }_{s}\right)+\sum_{\tau>0} \beta_{1}^{\tau} \text { incentive }_{d s t} \\
& +\beta_{2} \text { selection }_{d s t}+v_{s t}+u_{d s t} .
\end{aligned}
$$

From equation (14), we have that $\tau=\min \left[t-T_{s}, d\right]$ corresponds to the years lived under unilateral divorce laws for the cohort of couples who divorce in state $s$ in year $t$ of duration $d$, if unilateral divorce was introduced in year $T_{s}$. Hence, $\beta_{1}^{\tau}$ is the incentive effect of having lived under lower divorce costs for $\tau$ years. Figure 7 then plots the series of $\hat{\beta}_{1}^{\tau}$ coefficients for all $\tau \leq 20 .^{30}$ The omitted category is the incentive effect in the first year under lower divorce costs. Note

\footnotetext{
${ }^{30}$ The incentive effect varies between 0 and 20 years in over 95 percent of the duration-stateyear-level observations.
} 


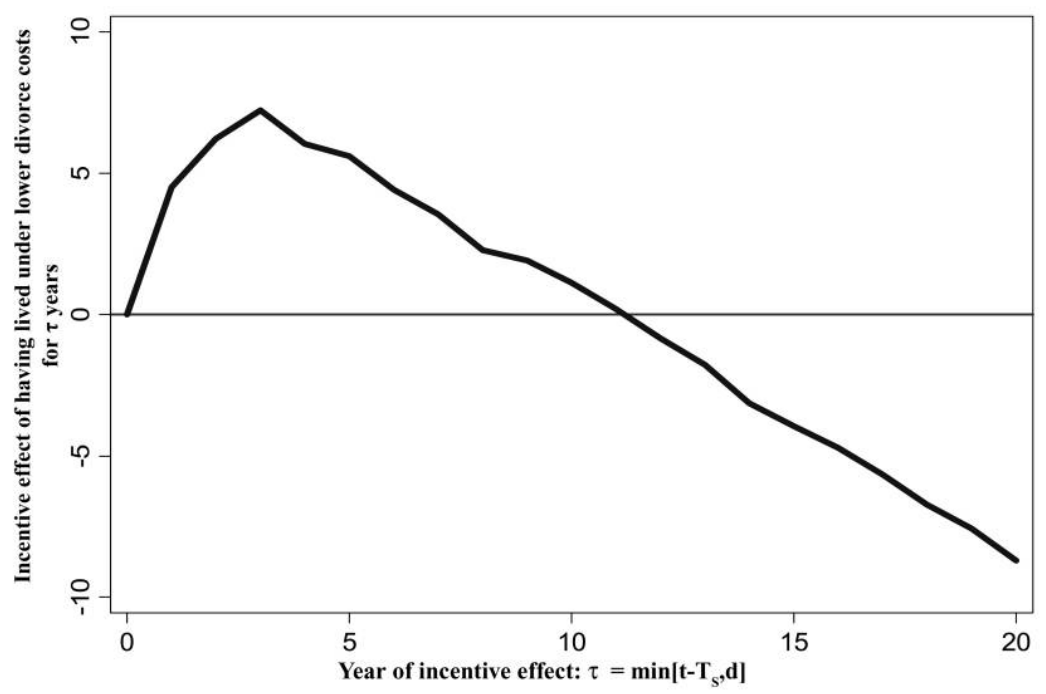

Figure 7. Dynamic incentive effect

that as the incentive effect partly relates to the year in which unilateral divorce was adopted within the state, and there is variation across states in the timing of that adoption, the sequence of $\hat{\beta}_{1}^{\tau}$ coefficients does not merely reflect a common time trend in divorce propensities.

Reassuringly, the pattern of coefficients in Figure 7 shows that for cohorts of married couples who live under unilateral divorce for up to 10 years, the propensity to divorce increases. However, for married couples who live under unilateral divorce laws for more than 10 years, the propensity to divorce falls. The magnitudes of these coefficients are consistent with those in the earlier regression analysis. There we estimated the incentive effect averaged over all years lived under unilateral divorce laws. The point estimate from the corresponding specification in column 4 of Table 3 was an average of these dynamic effects.

Note first that this result is in line with those of Gruber (2004) and Wolfers (2006), who find that the effects of unilateral divorce on aggregate divorce rates begin to disappear around a decade after its introduction. Second, the implied cumulative incentive effect, $\sum_{\tau>0} \hat{\beta}_{1}^{\tau}$, is .026 , so the implied probability of ever divorcing is higher as divorce costs fall, which is consistent with the predictions of all the models of marriage developed. As discussed in Section 4.3, this estimate is likely to underestimate the true change in the probability of ever divorcing because in equation (19) we difference out any common effect of lower divorce costs on all marriages within a state-year.

We are also able to estimate how the magnitude of the selection effect varies with the number of years that lower divorce costs are in place prior to marriage. 


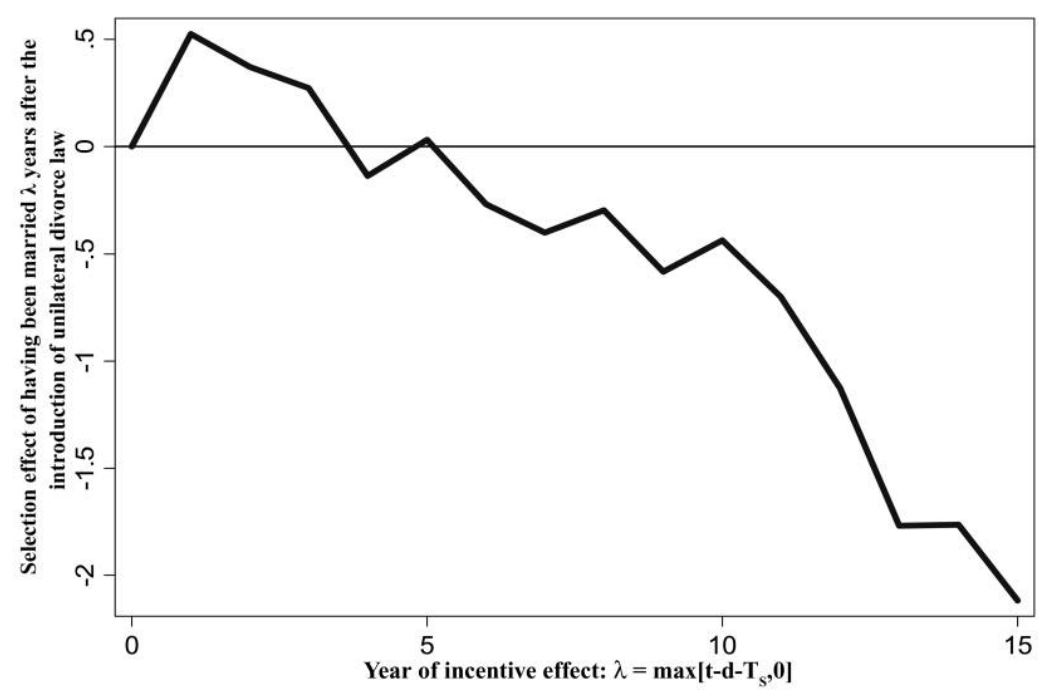

Figure 8. Dynamic selection effect

It is informative to estimate the varying magnitude of this effect for two reasons. First, the theory compares divorce propensities across two steady states with high and low divorce costs. The theory provides no prediction on the transition from one to the other. Second, if individuals anticipate a decline in divorce costs, there will be changes in the composition of couples who marry even under mutual-consent divorce laws. This situation biases the previously estimated selection effect toward zero.

We then modify the previous dynamic specification in equation (19) to also allow the selection effect to vary and so estimate the following panel data specification:

$$
\begin{aligned}
p_{d s t}= & \delta_{d}+\alpha_{s}+\sum_{\tau>0} \beta_{1}^{\tau} \text { incentive }_{d s t} \\
& +\sum_{\lambda>0} \beta_{2}^{\lambda} \text { selection }_{d s t}+v_{s t}+u_{d s t}
\end{aligned}
$$

and $\lambda=\max \left[t-d-T_{s}, 0\right]$ is the number of years prior to the year of marriage, if any, that unilateral divorce laws were in place. Hence, $\beta_{2}^{\lambda}$ is the selection effect of having been married $\lambda$ years after the introduction of unilateral divorce laws. We continue to condition on a full set of state-year fixed effects. Figure 8 then plots the series of $\hat{\beta}_{2}^{\lambda}$ coefficients for all $\lambda \leq 15{ }^{31}$

${ }^{31}$ The selection effect varies between 0 and 15 years in over 95 percent of the duration-stateyear-level observations. 
For couples married up to 3 years after the introduction of unilateral divorce, the propensity to divorce increases. For couples married 4 or more years after unilateral divorce laws are adopted, the propensity to divorce falls, other things being equal..$^{32}$ As we do not observe an immediate decline in divorce propensities with the introduction of unilateral divorce, this pattern of coefficients suggests that couples do not anticipate the reduction in divorce costs. Rather, it takes a few years after the introduction of unilateral divorce before the composition of couples who marry starts to adjust such that only couples of a higher match quality continue to marry, and this situation eventually causes divorce propensity to fall.

This finding can imply that the commitment motive for marriage has become much stronger over time and, in particular, has begun to be the dominant reason why couples chose to marry a few years after the introduction of unilateral divorce. This would be the case if, for example, the divorce law regime in place shapes how the population views the underlying purpose of marriage. An alternative interpretation of the data is that it takes time for individuals to learn how and to what extent divorce costs have fallen and to change their marriage market behavior accordingly. Disentangling these hypotheses is something we leave for future research.

\subsection{Heterogeneous Effects}

We now step outside the bounds of the theoretical analysis and investigate other sources of variation that may lead the incentive and selection effects of lower divorce costs to be heterogeneous across married couples. This analysis helps add weight to a causal interpretation of the incentive and selection effects previously estimated and highlights directions for further research.

\subsubsection{Labor Market Characteristics}

The first source of heterogeneity relates to the labor market characteristics where the couple lives. Some of these characteristics, such as the female labor force participation rate and the ratio of female-to-male earnings, reasonably proxy the relative bargaining power of women in the marriage market and, hence, the share of the marriage surplus that accrues to each partner. If there is assortative matching in the marriage market, and the surplus from marriage differs across couples depending on their labor market opportunities, then there should be variation in how sensitive couples are, on the margin, to a reduction in the costs of exiting marriage. With regard to the selection margin, a reduction in the costs of exiting marriage may reduce the incentives for spouses to invest in marital-specific capital or change the allocation of resources within marriage.

\footnotetext{
${ }^{32}$ The magnitudes of these coefficients are consistent with those in the earlier regression analysis. There we estimated the selection effect averaged over all married couples. The point estimate from the corresponding specification, -1.05 , was an average of these dynamic effects.
} 
Anticipating this, the marginal couple who chooses to marry may differ, hence changing the selection effect of lower divorce costs. ${ }^{33}$

We construct the labor market variables from the Current Population Survey at the state-year level. ${ }^{34}$ As these labor market variables are defined at the stateyear level, we drop the state-year fixed effects from specification (17) and instead control for the particular labor market characteristic $X_{s t}$ and an interaction between each characteristic and the incentive and selection effects. Hence, we estimate the following panel data specification:

$$
\begin{aligned}
p_{d s t}= & \delta_{d}+\alpha_{s}+\gamma_{t}+\sum_{d} \phi_{d}\left(\delta_{d} \times \text { adopt }_{s}\right)+\beta_{1} \text { incentive }_{d s t} \\
& +\beta_{11}\left(X_{s t} \times \text { incentive }_{d s t}\right)+\beta_{2} \text { selection }_{d s t} \\
& +\beta_{22}\left(X_{s t} \times \text { selection }_{d s t}\right)+\omega X_{s t}+u_{d s t} .
\end{aligned}
$$

We estimate this among all states and also among adopting states only. The parameters of interest are the interactions between the incentive and selection effects and each labor market characteristic, $\beta_{11}$ and $\beta_{22}$. All labor market characteristics are defined in terms of their deviations from their means. Hence, the incentive and selection effects, $\beta_{1}$ and $\beta_{2}$, are evaluated at the mean of the labor market variables. The results are reported in Table 4 .

The data in columns 1 and 2 show that among all states, the incentive effect of lower divorce costs is significantly higher (less negative) when the relative bargaining power of women increases, as measured by higher female labor force participation rates or a higher ratio of female-to-male earnings. In contrast, the selection effect is significantly lower (more negative) when female bargaining power increases. When we exploit only the variation in divorce propensities among adopting states, the results show a similar pattern.

The heterogeneous incentive effects suggest that as the bargaining power of women increases, couples become less likely to divorce after having lived under unilateral divorce laws for an additional year. This finding may capture the fact that there is positive assortative matching in marriage markets, so women with valuable outside options in the labor market tend to marry men with similarly high-valued outside options. If the marriage surplus from these relationships is higher, then, on the margin, these couples are expected to be less sensitive to changes in the costs of exiting marriage.

With regard to the selection effect, the results suggest that having been married an additional year after the introduction of unilateral divorce significantly reduces the divorce propensity, and this effect is stronger when women have more bar-

\footnotetext{
${ }^{33}$ Evidence that the introduction of unilateral divorce changes the allocation of resources within marriage has been found in the context of labor supply (Gray 1998; Chiappori, Fortin, and Lacroix 2002) and domestic violence (Stevenson and Wolfers 2006). Stevenson (2007) reports that divorce laws also have significant effects on marriage-specific investment, such as home ownership, children, and specialization in market versus nonmarket production.

${ }^{34}$ Details on the construction of each variable are provided in Appendix B.
} 
Table 4

Interactions with Labor Market Characteristics

\begin{tabular}{|c|c|c|c|c|}
\hline & \multicolumn{2}{|c|}{ All States } & \multicolumn{2}{|c|}{ Adopting States } \\
\hline & $\begin{array}{l}\text { Labor Force } \\
\text { Participation } \\
\text { (1) }\end{array}$ & $\begin{array}{c}\text { Earnings } \\
\text { Ratio } \\
(2)\end{array}$ & $\begin{array}{c}\text { Labor Force } \\
\text { Participation } \\
\text { (3) }\end{array}$ & $\begin{array}{c}\text { Earnings } \\
\text { Ratio } \\
(4)\end{array}$ \\
\hline Incentive effect & $\begin{array}{c}-.385^{\star *} \\
(.100)\end{array}$ & $\begin{array}{c}-.336^{* *} \\
(.094)\end{array}$ & $\begin{array}{r}-1.90^{* *} \\
(.242)\end{array}$ & $\begin{array}{r}-2.07^{\star *} \\
(.244)\end{array}$ \\
\hline \multicolumn{5}{|l|}{ Interaction with: } \\
\hline Female labor force participation rate & $\begin{array}{l}1.84^{\star \star} \\
(.435)\end{array}$ & & $\begin{array}{l}1.57^{\star *} \\
(.618)\end{array}$ & \\
\hline Ratio of female-to-male earnings & & $\begin{array}{l}1.12^{\star *} \\
(.407)\end{array}$ & & $\begin{array}{l}1.73^{\star *} \\
(.554)\end{array}$ \\
\hline Selection effect & $\begin{array}{l}.062 \\
(.052)\end{array}$ & $\begin{array}{l}.082^{+} \\
(.048)\end{array}$ & $\begin{array}{r}-1.49^{* *} \\
(.188)\end{array}$ & $\begin{array}{r}-1.69^{\star *} \\
(.191)\end{array}$ \\
\hline \multicolumn{5}{|l|}{ Interaction with: } \\
\hline Female labor force participation rate & $\begin{array}{r}-2.70^{* *} \\
(.448)\end{array}$ & & $\begin{array}{r}-2.89^{\star *} \\
(.519)\end{array}$ & \\
\hline Ratio of female-to-male earnings & & $\begin{array}{r}-3.16^{\star *} \\
(.430)\end{array}$ & & $\begin{array}{r}-2.62^{\star *} \\
(.538)\end{array}$ \\
\hline Duration $\times$ adopting state interactions & Yes & Yes & No & No \\
\hline Adjusted $R^{2}$ & .8418 & .8397 & .8545 & .8515 \\
\hline Number of observations & 11,482 & 11,428 & 6,471 & 6,471 \\
\hline
\end{tabular}

Note. The dependent variable is (number of divorces in state $s$, year $t$, of duration $d) /(1,000 \times$ number of marriages in state $s$ in year $t-d)$. Standard errors are in parentheses and are clustered by state-duration. All specifications control for duration and state and year fixed effects, and the data in columns 1 and 2 also include a series of interactions between whether the state ever adopts unilateral divorce and the duration fixed effects. The sample used for the data in columns 1 and 2 covers 33 states. The sample used for the data in columns 3 and 4 covers 19 states that adopted unilateral divorce laws at some point. All data are based on divorces that have taken place since 1968 and prior to 1995. All interaction terms are defined in deviations from means. The March rounds of the Current Population Survey (CPS) are used to construct the labor market variables at the state-year level using CPS weights. Both labor market characteristic variables are measured in terms of their deviations from their means.

+ Statistically significant at the $10 \%$ level.

** Statistically significant at the $1 \%$ level.

gaining power. This finding implies that the use of the marriage contract as a commitment device is relatively stronger when women have more bargaining power, other things being equal. These implications clearly deserve further research. ${ }^{35}$

\subsubsection{Social Characteristics}

We now explore whether the incentive and selection effects differ with the social characteristics in the state in which a given couple lives. We exploit two measures of these characteristics. First, we use the percentage of the state population that is Catholic. A high percentage may be indicative of higher social costs of divorce, and, hence, in states with high percentages of Catholics, the

${ }^{35}$ We have also estimated these specifications including state-year fixed effects. The sign and significance of the results are largely unchanged when we do this although, as expected, the magnitudes of the coefficients change. 
incentive and selection effects arising from the introduction of unilateral divorce laws may be mitigated. ${ }^{36}$

Our second approach uses information on the permissiveness of divorce laws that is based on an index constructed by Broel-Plateris (1961). This index is calculated from responses to a questionnaire administered to 68 family law experts in each state. It is designed to reflect whether states have systematically different standards of evidence and perjury in divorce cases. As such, it serves as a proxy for judicial attitudes and social norms toward divorce in the early 1960s, predating the introduction of unilateral divorce. The index varies crosssectionally across states and runs from 0 (least permissive) to 100 (most permissive). The incentive and selection effects of lower divorce costs should be lower in more permissive states, because in those states, the interpretation and practice of the law is such that divorce costs are lower to begin with. ${ }^{37}$

For each social characteristic, we estimate a specification similar to that in equation (21), both among all states and then among adopting states only. The parameters of interest are the interactions between the incentive and selection effects and each social characteristic. All characteristics are defined in terms of their deviations from their means. Hence, the incentive and selection effects are evaluated at the mean of the social variables. The results are reported in Table 5.

The data show that among all states, where the share of the population that is Catholic is higher than average, the incentive effect of having lived an additional year under unilateral divorce laws is significantly higher (less negative), all else being equal. At the same time, the selection effect of having been married an additional year after the introduction of unilateral divorce is significantly lower (more negative), all else being equal. The data in column 3 show that the sign, significance, and magnitude of these heterogeneous effects are similar among the subset of adopting states.

The incentive effect result implies that where there is a greater share of Catholics among the population, married couples are less affected by a reduction in divorce costs as proxied by unilateral divorce laws. Presumably this is because in these states the social costs of divorce remain relatively high irrespective of the legal regime governing divorce. The selection effect result suggests that where a greater share of the population is Catholic, the commitment motive for entering into a marriage contract is relatively stronger, perhaps because the underlying reasons for entering into a marriage contract are different for Catholics and non-Catholics.

On the permissiveness of divorce laws, the results in column 2 show that in states in which divorce laws are more permissive to begin with, the incentive effect of having lived an additional year under unilateral divorce laws is significantly lower (more negative), all else being equal. At the same time, the selection

\footnotetext{
${ }^{36}$ Catholics have lower divorce rates (Bumpass and Sweet 1972; Freiden 1974) and a higher age at marriage (Michael and Tuma 1985; Mosher, Williams, and Johnson 1992) than non-Catholics.

${ }^{37}$ Further details of this index are reported in Stetson and Wright (1975). They find a positive correlation between this index and actual divorce laws in place, as well as with divorce rates themselves.
} 
Table 5

Interactions with Social Characteristics

\begin{tabular}{|c|c|c|c|c|}
\hline & \multicolumn{2}{|c|}{ All States } & \multicolumn{2}{|c|}{ Adopting States } \\
\hline & $\begin{array}{l}\text { Catholic } \\
\text { (1) }\end{array}$ & $\begin{array}{l}\text { Permissiveness } \\
\text { (2) }\end{array}$ & $\begin{array}{l}\text { Catholic } \\
\text { (3) }\end{array}$ & $\begin{array}{c}\text { Permissiveness } \\
\text { (4) }\end{array}$ \\
\hline Incentive effect & $\begin{array}{l}-.139 \\
(.103)\end{array}$ & $\begin{array}{r}-.090 \\
(.100)\end{array}$ & $\begin{array}{l}-.909^{* *} \\
(.309)\end{array}$ & $\begin{array}{l}-.898^{\star *} \\
(.305)\end{array}$ \\
\hline Interaction with: & & & & \\
\hline Percentage Catholic & $\begin{array}{l}2.60^{\star *} \\
(.330)\end{array}$ & & $\begin{array}{l}2.54^{* *} \\
(.328)\end{array}$ & \\
\hline Permissiveness index & & $\begin{array}{l}-.018^{* *} \\
(.002)\end{array}$ & & $\begin{array}{l}-.018^{* *} \\
(.002)\end{array}$ \\
\hline Selection effect & $\begin{array}{l}-.172^{\star *} \\
(.039)\end{array}$ & $\begin{array}{l}-.105^{\star *} \\
(.039)\end{array}$ & $\begin{array}{r}-1.02^{\star *} \\
(.241)\end{array}$ & $\begin{array}{l}-.996^{\star *} \\
(.241)\end{array}$ \\
\hline Interaction with: & & & & \\
\hline Percentage Catholic & $\begin{array}{r}-1.26^{\star *} \\
(.203)\end{array}$ & & $\begin{array}{r}-1.34^{* *} \\
(.204)\end{array}$ & \\
\hline Permissiveness index & & $\begin{array}{l}.008^{\star *} \\
(.001)\end{array}$ & & $\begin{array}{l}.008^{\star *} \\
(.001)\end{array}$ \\
\hline $\begin{array}{l}\text { Duration } \times \text { adopting } \\
\text { state interactions }\end{array}$ & Yes & Yes & No & No \\
\hline Adjusted $R^{2}$ & .8471 & .8467 & .8684 & .8695 \\
\hline Number of observations & 12,113 & 11,576 & 7,057 & 6,288 \\
\hline
\end{tabular}

Note. The dependent variable is (number of divorces in state $s$, year $t$, of duration $d) /(1,000 \times$ number of marriages in state $s$ in year $t-d)$. Standard errors are in parentheses and are clustered by state-duration. All specifications control for duration and state and year fixed effects, and the data in columns 1 and 2 also include a series of interactions between whether the state ever adopts unilateral divorce and the duration fixed effects. The sample used for the data in columns 1 and 2 covers 33 states. The sample used for the data in columns 3 and 4 covers 19 states that adopted unilateral divorce at some point. The data are based on divorces that have taken place since 1968 and prior to 1995. All interaction terms are defined in deviations from means. The measure of the permissiveness of the divorce laws in place is based on an index constructed by Broel-Plateris (1961). Both social characteristic variables are measured in terms of their deviations from their means.

${ }^{*}$ Statistically significant at the $1 \%$ level.

effect of having been married an additional year after the introduction of unilateral divorce is significantly higher (less negative), all else being equal. The data in column 4 confirm these findings among the subset of adopting states. This result suggests that in states with preexisting liberal attitudes toward divorce, the commitment motive for entering into a marriage contract may be relatively weaker.

\section{Conclusion}

Marriage contracts are among the most prevalent forms of contract in human society, yet economists know relatively little about why people decide to marry and enter into such contracts. The vast literature on the economics of marriage that followed Becker's $(1973,1974)$ seminal contribution has focused on the gains from being together relative to being single. This literature provides fewer insights into why couples choose to marry rather than cohabit. In contrast, this 
article focuses directly on the reasons why individuals agree to sign marriage contracts.

We have formalized three models of the marriage contract that have been discussed informally in the law and economics literature. We then provide empirical evidence to identify which model can best be reconciled with data from the U.S. marriage market. Our findings suggest that the dominant role of the marriage contract is to act as a commitment device.

Our results speak directly to the current policy debate on if and how divorce laws should be reformed (see, for instance, Kaye 2006; Matrimonial Commission 2006; Hakim 2006). When marriage serves as a commitment device, a reform that reduces the costs of divorce, such as the move to unilateral divorce laws, can undermine the purpose of the marriage contract. Indeed, it can easily be shown that in the commitment model, divorce costs can be too low and that, in such a case, a reform that increases divorce costs would lead to higher marriage rates and lower divorce rates. In this context, it is interesting to note that survey evidence suggests large segments of the population support higher divorce costs and believe that such a reform would "save the institution of marriage." 38

Absent such a reform, couples should search for alternative commitment devices when they believe that marriage no longer provides enough commitment power. The demand for covenant marriages, which are licensing procedures that are specifically designed to make marital breakups more costly, suggests that some couples do indeed seek more effective commitment devices. Covenant marriage bills have already been enacted by state legislatures in Arizona, Arkansas, and Louisiana and have been discussed in many other states (see Economist 1997; Jones 1998).

Our results also relate to the debate on gay marriage and suggest that by not allowing homosexuals to marry, current marriage laws destabilize relationships between homosexuals and thus impose an economic cost on them. Currently, such efficiency considerations are largely absent from the policy debate on gay marriage, which focuses on moral and fairness concerns (see Economist 2004).

Throughout our analysis, we have assumed that the sole effect of divorce law reform was to reduce the costs of getting divorced and have abstracted from other potential effects, such as a reduction in the prestige associated with getting married. We have done so since these other effects are less well understood and likely to be of second-order importance relative to the reduction in divorce costs themselves. It should be noted, however, that each model could be extended to incorporate such additional effects, whereby the benefits of marriage are also partly endogenously determined by divorce costs. We leave the analysis of such alternative models and their empirical predictions for future work.

Another natural extension of our analysis would be to integrate a model of

${ }^{38}$ Between 1974 and 2002, the General Social Survey has asked a representative sample of American adults, "Should divorce in this country be easier or more difficult to obtain than it is now?" Every survey shows that a majority or plurality of Americans think divorce should be made "more difficult." See also Wetzstein (2004). 
marital bargaining into the theoretical framework. This integration would make precise how the outside options of spouses in marital bargaining influence the sign and magnitude of the incentive and selection effects of divorce costs. ${ }^{39}$ It would also provide an empirical framework in which to further explore the potential heterogeneous effects of unilateral divorce laws across different married couples and to analyze the effects of other legal reforms, such as those begun in the mid-1980s on the division of marital assets and allocation of child custody.

Finally, in analyzing marriage as a commitment device, we have focused on its role in facilitating cooperation in a repeated setting. It is evident, however, that there are also other ways in which marriage can serve as a commitment device. ${ }^{40}$ Since any model in which marriage serves as a commitment device would be consistent with a positive selection effect, our results do not allow us to distinguish between such models of commitment. We leave this task for future work.

\section{Appendix A}

\section{Proofs of Lemmas and Propositions}

This appendix provides proofs of the lemmas and propositions in the main text and provides additional information on the models developed in Section 3.

\section{Proof of Lemma 1}

Implicitly differentiating equations (1) and (2) gives

$$
\frac{d V_{\mathrm{c}}}{d b}=\frac{1}{1-r F\left(r V_{\mathrm{c}}\right)}>0 \quad \text { and } \quad \frac{d V_{\mathrm{m}}}{d b}=\frac{1}{1-r F\left(r V_{\mathrm{m}}+\gamma\right)}>0 .
$$

Thus, the values of cohabitation and of marriage are both increasing in the match quality of a couple, $b$. Observe also that $d V_{\mathrm{c}} / d b<d V_{\mathrm{m}} / d b$ if $V_{\mathrm{c}}=V_{\mathrm{m}}$. Finally, recall that we assume that $B$ is small enough that some couples find it optimal not to marry. It then follows that there exists a unique $\bar{b}$ such that $V_{\mathrm{m}} \geq V_{\mathrm{c}}$ if $b \geq \bar{b}$, and $V_{\mathrm{m}}<V_{\mathrm{c}}$ otherwise. Q.E.D.

\section{Proof of Proposition 1}

Using equations (1) and (2) and implicitly differentiating gives

$$
\frac{d \bar{b}}{d \gamma}=\frac{(1-F(r V+\gamma))(1-r F(r V))}{r(F(r V+\gamma)-F(r V))}>0
$$

\footnotetext{
${ }^{39}$ See, for instance, Wickelgren (2005). Similar to our argument, he shows that divorce reform can affect divorce rates both directly and indirectly by changing selection into marriage.

${ }^{40}$ For example, Scott (2002) suggests that agents with hyperbolic preferences who anticipate that they will not be able to resist the temptation of an affair in the future, but also know that such an affair hurts them in the long run, may want to marry to "tie their hands."
} 
where $V=V_{\mathrm{m}}=V_{c}$. Next, differentiating equation (4) gives

$$
\frac{\partial P_{d}}{\partial \bar{b}}=\frac{h(\bar{b})}{1-H(\bar{b})}\left(P_{d}-p_{d}(\bar{b})\right)<0,
$$

where $p_{d}(\bar{b})$ is $p_{d}$ evaluated for $b=\bar{b}$. Since $d \bar{b} / d \gamma>0$ and $d P_{d} / d \bar{b}<0$, it follows that the selection effect is negative. Next, differentiating equation (4) gives

$$
\frac{\partial P_{d}}{\partial \gamma}=\frac{1-r}{1-H(\bar{b})} \int_{\bar{b}}^{\infty} \frac{F(\cdot)^{d-2} f(\cdot)}{1-r F(\cdot)}[(d-1)(1-F(\cdot))-F(\cdot)] d H(b) .
$$

Note that this expression is negative for $d=1$. Thus, there exists a $\underline{d}>1$ such that $\partial P_{d} / \partial \gamma<0$ if $d<\underline{d}$. Next, note that $F\left(r V_{m}+\gamma\right)<1$ for all $b$. It follows that for large enough $d$, the term in square brackets in equation (A1) is positive for all $b$. This, in turn, implies that there exists a $\bar{d} \geq d$ such that $\partial P_{d} / \partial \gamma>0$ if $d \geq \bar{d}$. Finally, it follows from equation (A1) that the cumulative incentive effect is given by

$$
\frac{\partial P_{d}^{\Sigma}}{\partial \gamma}=\sum_{t=1}^{d} \frac{\partial P_{t}}{\partial \gamma}=-\frac{1-r}{1-H(\bar{b})} \int_{\bar{b}}^{\infty} d \frac{F(\cdot)^{d-1} f(\cdot)}{1-r F(\cdot)} d H(b)<0 .
$$

Q.E.D.

\section{Proof of Lemma 2}

Consider first the reneging constraint (8). Note that the constraint is strictly satisfied for $b=c$ since in this case the right-hand side is equal to zero. Note also that the left-hand side increases in $b$ at rate 1 and that the right-hand side increases in $b$ at rate $1 /\left(1-r F\left(r V_{\mathrm{m}}+\gamma\right)\right)>1$. Thus, there exists a unique $\underline{b}_{1}$ such that equation (8) is satisfied if and only if $b \geq \underline{b}_{1}$.

Consider next the reneging constraint (9). Note that the constraint is strictly satisfied for $b=c$ since in this case the right-hand side is equal to zero. Note also that the left-hand side increases in $b$ at rate 1 and that the right-hand side increases in $b$ at rate $1 /\left(1-r F\left(r V_{c}\right)\right)>1$. Thus, there exists a unique $\bar{b}$ such that equation (9) is satisfied if and only if $b \geq \bar{b}$.

To establish that $\bar{b}>\underline{b}_{1}$ we need to show that $V_{\mathrm{m}}-U_{\mathrm{m}}>V_{\mathrm{c}}-U_{\mathrm{c}}$. To see that this is indeed the case, note first that $V_{\mathrm{m}}-U_{\mathrm{m}}=V_{\mathrm{c}}-U_{\mathrm{c}}$ if $\gamma=0$. Note next that

$$
\frac{d V_{\mathrm{m}}}{d \gamma}=-\frac{1-F\left(r V_{\mathrm{m}}+\gamma\right)}{1-F\left(r V_{\mathrm{m}}+\gamma\right)}>-\frac{1-F\left(r U_{\mathrm{m}}+\gamma\right)}{1-F\left(r U_{\mathrm{m}}+\gamma\right)}=\frac{d U_{\mathrm{m}}}{d \gamma},
$$

where the expressions for $d V_{\mathrm{m}} / d \gamma$ and $d U_{\mathrm{m}} / d \gamma$ are obtained by implicitly differentiating equations (6) and (7). Thus, $V_{\mathrm{m}}-U_{\mathrm{m}}>V_{\mathrm{c}}-U_{\mathrm{c}}$ for any $\gamma>0$. Q.E.D. 
Proof of Lemma 3

The payoff from cooperating and being married is given by $V_{\mathrm{m}}$, and the payoff from not cooperating and cohabiting is given by $U_{c}$. Note that $V_{\mathrm{m}}<U_{\mathrm{c}}$ for $b=c$ and that $V_{\mathrm{m}}$ is increasing in $b$ while $U_{\mathrm{c}}$ is independent of $b$. Thus, there exists a unique $\underline{b}_{2}$ such that $V_{\mathrm{m}} \geq U_{\mathrm{c}}$ if and only if $b \geq \underline{b}_{2}$. Q.E.D.

\section{Proof of Lemma 4}

Lemma 4 follows immediately from the discussion in the text. Q.E.D.

\section{Proof of Proposition 2}

Consider first $\underline{b}_{1}$, which is the unique $b$ that solves equation (8) with equality. Recall from the proof of lemma 2 that the left-hand side increases in $b$ at rate 1 and that the right-hand side increases in $b$ at rate $1 /\left(1-r F\left(r V_{\mathrm{m}}+\gamma\right)\right)>1$. Recall also from that proof that the right-hand side is increasing in $\gamma$. This situation implies that $d \underline{b}_{1} / d \gamma<0$. Consider next $\underline{b}_{2}$, which is the unique $b$ that solves $V_{\mathrm{m}}=U_{\mathrm{c}}$. By implicitly differentiating, we get

$$
\frac{d \underline{b}_{2}}{d \gamma}=\left(1-F\left(r V_{\mathrm{m}}+\gamma\right)\right)>0 \text {. }
$$

Finally, differentiating equation (10) gives

$$
\frac{d P_{d}}{d \underline{b}}=\frac{h(\underline{b})}{H(\bar{b})-H(\underline{b})}\left(P_{d}-p_{d}(\underline{b})\right)<0,
$$

where $p_{d}(\underline{b})$ is $p_{d}$ evaluated for $b=\underline{b}$. It follows that the selection effect is negative if $\underline{b}_{2}>\underline{b}_{1}$ and is positive otherwise. Next, differentiating equation (10) gives

$$
\frac{\partial P_{d}}{\partial \gamma}=\frac{1-r}{H(\bar{b})-H(\underline{b})} \int_{\bar{b}}^{\infty} \frac{F(\cdot)^{d-2} f(\cdot)}{1-r F(\cdot)}[(d-1)(1-F(\cdot))-F(\cdot)] d H(b) .
$$

Note that this expression is negative for $d=1$. Thus, there exists a $\underline{d}>1$ such that $\partial P_{d} / \partial \gamma<0$ if $d<\underline{d}$. Next, note that $F\left(r V_{m}+\gamma\right)<1$ for all $b$. It follows that for large enough $d$, the term in square brackets in equation (A2) is positive for all $b$. This, in turn, implies that there exists a $\bar{d} \geq \underline{d}$ such that $\partial P_{d} / \partial \gamma>0$ if $d \geq \bar{d}$. Finally, it follows from equation (A2) that the cumulative incentive effect is given by

$$
\frac{\partial P_{d}^{\Sigma}}{\partial \gamma}=\sum_{t=1}^{d} \frac{\partial P_{t}}{\partial \gamma}=-\frac{1-r}{H(\bar{b})-H(\underline{b})} \int_{\bar{b}}^{\infty} d \frac{F(\cdot)^{d-1} f(\cdot)}{(1-r F(\cdot))} d H(b)<0 .
$$

Q.E.D.

\section{Proof of Lemma 5}

A man prefers cohabitation to breaking up if and only if $V_{c}-c_{M} \geq E(s)$. Note that this inequality is not satisfied for $b=0$ and that the left-hand side is 
increasing in $b$ while the right-hand side is not. Thus, there exists a $\underline{b}$ such that a man prefers cohabitation to breaking up if and only if $b \geq \underline{b}$.

A man prefers marriage to breaking up if and only if $V_{\mathrm{m}}-c_{\mathrm{M}} \geq E(s)$. Note that this inequality is not satisfied for $b=0$ and that the left-hand side is increasing in $b$ while the right-hand side is not. Thus, there exists a $\bar{b}$ such that a man prefers marriage to breaking up if and only if $b \geq \bar{b}$. Finally, $\bar{b}>\underline{b}$ since $V_{\mathrm{c}}>V_{\mathrm{m}}$. Q.E.D.

In Section 3.3, we informally stated the assumption that " $c_{\mathrm{w}}$ is large enough relative to $c_{\mathrm{M}}$ so women do not want to start a relationship with the average man who prefers cohabitation to being single." We have now introduced the notation that allows us to state this assumption formally. In particular, we assume that

$$
\int_{\underline{b}}^{\infty} V_{c} d H(b) /(1-H(\underline{b}))-c_{\mathrm{W}}<E(s) .
$$

Note that this inequality is satisfied when $c_{\mathrm{w}}$ is "large enough" but is not satisfied when $c_{\mathrm{W}}=c_{\mathrm{M}}$.

\section{Proof of Lemma 6}

Suppose that women believe that men propose marriage if and only if $b \geq$ $\bar{b}$, that they propose cohabitation if and only if $\underline{b} \leq b<\bar{b}$, and that they break up otherwise. Then it is optimal for women to accept a marriage proposal if and only if

$$
\int_{\bar{b}}^{\infty} V_{\mathrm{m}} d H(b) /(1-H(\bar{b}))-c_{\mathrm{w}} \geq E(s) .
$$

Note that this condition is satisfied if $c_{\mathrm{W}}$ is "not too large." Next, given assumption (A3) and women's beliefs, it is optimal for them to turn down any cohabitation proposal. Given these strategies, it is optimal for men to propose marriage if and only if $b \geq \bar{b}$ and to break up otherwise. Finally, given these strategies for men and women, the beliefs assumed at the beginning of the proof are consistent. Q.E.D.

\section{Proof of Proposition 3}

Using equations (1) and (2) and implicitly differentiating gives

$$
\frac{d \bar{b}}{d \gamma}=\frac{(1-F(r V+\gamma))(1-r F(r V))}{r(F(r V+\gamma)-F(r V))}>0,
$$

where $V=V_{\mathrm{m}}=V_{c}$. Next, differentiating equation (4) gives

$$
\frac{d P_{d}}{d \bar{b}}=\frac{h(\bar{b})}{1-H(\bar{b})}\left(P_{d}-p_{d}(\bar{b})\right)<0,
$$


where $p_{d}(\bar{b})$ is $p_{d}$ evaluated for $b=\bar{b}$. Since $\partial \bar{b} / \partial \gamma$ and $\partial P_{d} / \partial \bar{b}<0$, it follows that the selection effect is negative. Next, differentiating equation (4) gives

$$
\frac{\partial P_{d}}{\partial \gamma}=\frac{1-r}{1-H(\bar{b})} \int_{\bar{b}}^{\infty} \frac{F(\cdot)^{d-2} f(\cdot)}{1-r F(\cdot)}[(d-1)(1-F(\cdot))-F(\cdot)] d H(b) .
$$

Note that this expression is negative for $d=1$. Thus, there exists a $\underline{d}>1$ such that $\partial P_{d} / \partial \gamma<0$ if $d<\underline{d}$. Next, note that $F\left(r V_{m}+\gamma\right)<1$ for all $b$. It follows that for large enough $d$, the term in square brackets in equation (A5) is positive for all $b$. This, in turn, implies that there exists a $\bar{d} \geq \underline{d}$ such that $\partial P_{d} / \partial \gamma<0$ if $d \geq \bar{d}$. Finally, it follows from equation (A5) that the cumulative incentive effect is given by

$$
\frac{\partial P_{d}^{\Sigma}}{\partial \gamma}=\sum_{t=1}^{d} \frac{\partial P_{t}}{\partial \gamma}=-\frac{1-r}{1-H(\bar{b})} \int_{\bar{b}}^{\infty} d \frac{F(\cdot)^{d-1} f(\cdot)}{(1-r F(\cdot))} d H(b)<0 .
$$

Q.E.D.

\section{Appendix B}

\section{Data Sources}

Marriage and divorce certificate data were obtained from the National Vital Statistics System of the National Center for Health Statistics, for all years between 1968 and $1995 .^{41}$ Marriage certificate data include the date of marriage, state residency, education, previous marital status, number of marriages, and ages of bride and groom. These data cover around 44 states, depending on the year. Divorce certificate data include marital duration, number of children under 18, month and year of marriage, number of marriages, age, race, and state residency of husband and wife, and the allocation of child custody is recorded after 1989. Divorce certificate data cover 26 states in 1968, 28 in 1969-70, 30 in 1971-77, 28 in 1978, 31 in 1979-80, 32 in 1981-85, and 33 after 1986. Marriages or divorces of members of the armed forces or other U.S. nationals that occur outside of the United States are excluded. We construct marital duration-stateyear-specific divorce propensities for the following: Alaska, Arkansas, California, Connecticut, Delaware, the District of Columbia, Georgia, Hawaii, Idaho, Illinois, Iowa, Kansas, Kentucky, Maryland, Massachusetts, Michigan, Missouri, Montana, Nebraska, New Hampshire, New York, Ohio, Oregon, Pennsylvania, Rhode Island, South Carolina, South Dakota, Tennessee, Utah, Vermont, Virginia, Wisconsin, and Wyoming.

The March rounds of the Current Population Survey (CPS) are used to construct the state-level labor market variables using the CPS weights. From 1968 to 1972, the following areas are identified: California, the District of Columbia,

${ }^{41}$ These data are also downloadable. See National Center for Health Statistics, NCHS's Marriage and Divorce Data 1968-1995 (http://www.nber.org/data/marrdivo.html). 
Florida, Georgia, Illinois, Indiana, Kentucky, Louisiana, Maryland, Missouri, New Jersey, New York, Ohio, Oregon, Pennsylvania, Tennessee, and West Virginia. From 1973 to 1976, California, Connecticut, the District of Columbia, Florida, Illinois, Indiana, Massachusetts, North Carolina, New Jersey, New York, Ohio, and Pennsylvania are identified. After 1976, state-level aggregates can be constructed for 43 states. Labor market characteristics are based on the following definition of participation in the labor force: the individual must be between 16 and 64 years old (60 for women), employed full time, not in school, and have worked for at least 1 week.

\section{References}

Becker, Gary. 1973. A Theory of Marriage: Part I. Journal of Political Economy 81:813-46. - 1974. A Theory of Marriage: Part II. Journal of Political Economy 82:S11-S26.

Bergstrom, Theodore. 1997. A Survey of Theories of the Family. Pp. 21-59 in Handbook of Population and Family Economics, edited by Mark Rosenzweig and Oded Stark. Amsterdam: Elsevier.

Bertrand, Marianne, Esther Duflo, and Sendhil Mullainathan. 2005. How Much Should We Trust Differences-in-Differences Estimates? Quarterly Journal of Economics 119: 249-75.

Bishop, William. 1984. “Is He Married?” Marriage as Information. University of Toronto Law Journal 34:245-63.

Brien, Michael, Lee Lillard, and Steven Stern. 2006. Cohabitation, Marriage, and Divorce in a Model of Match Quality. International Economic Review 47:451-94.

Brinig, Margaret, and Steven Crafton. 1994. Marriage and Opportunism. Journal of Legal Studies 23:869-94.

Broel-Plateris, Alexander. 1961. Marriage Disruption and Divorce Law in the United States. Unpublished doctoral dissertation. University of Chicago, Department of Sociology, Chicago.

Bumpass, Larry, and James Sweet. 1972. Differentials in Marital Instability: 1970. American Sociological Review 37:754-66.

Chiappori, Pierre-André, Bernard Fortin, and Guy Lacroix. 2002. Marriage Market, Divorce Legislation, and Household Labor Supply. Journal of Political Economy 110:37-72.

Chiappori, Pierre-André, Murat Iyigun, and Yoram Weiss. 2005. Spousal Matching, Marriage Contracts, and Property Division in Divorce. Unpublished manuscript. Columbia University, Department of Economics, New York.

Cohen, Lloyd. 1987. Marriage, Divorce, and Quasi Rents; or, "I Gave Him the Best Years of My Life." Journal of Legal Studies 16:267-303.

- 2002. Marriage: The Long-Term Contract. Pp. 10-34 in The Law and Economics of Marriage and Divorce, edited by Antony Dnes and Robert Rowthorn. Cambridge: Cambridge University Press.

Dnes, Antony, and Robert Rowthorn. 2002. The Law and Economics of Marriage and Divorce. Cambridge: Cambridge University Press.

Economist. 1997. Strengthening Marriage. August 9.

—. 2004. The Case for Gay Marriage. February 28.

Edlund, Lena. 2005. The Role of Paternity Presumption and Custodial Rights for Un- 
derstanding Marriage Patterns. Unpublished manuscript. Columbia University, Department of Economics, New York.

Ellman, Ira, and Sharon Lohr. 1998. Dissolving the Relationship between Divorce Laws and Divorce Rates. International Review of Law and Economics 18:341-59.

Ermisch, John. 2003. An Economic Analysis of the Family. Princeton, N.J.: Princeton University Press.

Freiden, Alan. 1974. The United States Marriage Market. Journal of Political Economy 82: 534-53.

Friedberg, Leora. 1998. Did Unilateral Divorce Raise Divorce Rates? Evidence from Panel Data. American Economic Review 88:608-27.

Friedberg, Leora, and Steven Stern. 2004. Marriage, Divorce, and Asymmetric Information. Unpublished manuscript. University of Virginia, Department of Economics, Charlottesville.

Goldin, Claudia, and Lawrence Katz. 2002. The Power of the Pill: Oral Contraceptives and Women's Career and Marriage Decisions. Journal of Political Economy 110:730-70.

Gray, Jeffrey. 1998. Divorce Law Changes, Household Bargaining, and Married Women's Labor Supply. American Economic Review 88:628-42.

Gruber, John. 2004. Is Making Divorce Easier Bad for Children? The Long Run Implications of Unilateral Divorce. Journal of Labor Economics 22:799-833.

Hakim, Danny. 2006. Panel Asks New York to Join the Era of No-Fault Divorce. New York Times, February 7.

Jones, Tamara. 1998. The Commitment. Washington Post, May 10.

Kaye, Judith. 2006. The State of the Judiciary. http://nycourts.gov/admin/stateofjudiciary/ soj2006.pdf.

Lundberg, Shelly, and Robert Pollak. 1993. Separate Spheres Bargaining and the Marriage Market. Journal of Political Economy 101:988-1010.

Matrimonial Commission. 2006. Matrimonial Commission: Report to the Chief Justice of the State of New York. http://www.nycourts.gov/reports/matrimonialcommissionreport .pdf.

Mechoulan, Stéphane. 2006. Divorce Laws and the Structure of the American Family. Journal of Legal Studies 35:143-74.

Michael, Robert, and Nancy Tuma. 1985. Entry into Marriage and Parenthood by Young Men and Women: The Influence of Family Background. Demography 22:515-44.

Mosher, William, Linda Williams, and David Johnson. 1992. Religion and Fertility in the United States: New Patterns. Demography 29:199-214.

Parkman, Allan. 1992. No-Fault Divorce: What Went Wrong? San Francisco: Westview Press.

Peters, Elisabeth. 1986. Marriage and Divorce: Informational Constraints and Private Contracting. American Economic Review 76:437-54.

Rasul, Imran. 2005. The Impact of Divorce Laws on Marriage. Unpublished manuscript. University of Chicago, Graduate School of Business, Chicago.

Rowthorn, Robert. 2002. Marriage as a Signal. Pp. 132-56 in The Law and Economics of Marriage and Divorce, edited by Antony Dnes and Robert Rowthorn. Cambridge: Cambridge University Press.

Scott, Elisabeth. 1990. Rational Decision-Making about Marriage and Divorce. Virginia Law Review 76:9-94.

- 2002. Marital Commitment and the Legal Regulation of Divorce. Pp. 35-56 in 
The Law and Economics of Marriage and Divorce, edited by Antony Dnes and Robert Rowthorn. Cambridge: Cambridge University Press.

Stetson, Dorothy, and Gerald Wright. 1975. The Effects of Laws on Divorce in American States. Journal of Marriage and the Family 37:537-47.

Stevenson, Betsy. 2007. The Impact of Divorce Laws on Investment in Marriage-Specific Capital. Journal of Labor Economics 25:75-94.

Stevenson, Betsy, and Justin Wolfers. 2006. Bargaining in the Shadow of the Law: Divorce Laws and Family Distress. Quarterly Journal of Economics 121:267-88.

Trebilcock, Michael. 1999. Marriage as a Signal. Pp. 245-55 in The Fall and Rise of Freedom of Contract, edited by Francis Buckley. Durham, N.C.: Duke University Press.

Waite, Linda, and Maggie Gallagher. 2000. The Case for Marriage. New York: Broadway Books.

Weiss, Yoram. 1997. The Formation and Dissolution of Families: Why Marry? Who Marries Whom? And What Happens upon Divorce. Pp. 81-123 in Handbook of Population and Family Economics, edited by Mark Rosenzweig and Oded Star. Amsterdam: Elsevier.

Weiss, Yoram, and Robert Willis. 1997. Match Quality, New Information, and Marital Dissolution. Journal of Labor Economics 15:S293-S299.

Wetzstein, Cheryl. 2004. Breaking up Isn't Hard Enough to Do: Public Backs Making Divorce Difficult. Washington Times, February 1.

Wickelgren, Abraham. 2005. Why Divorce Laws Matter: Incentives for Non-contractible Marital Investments under Unilateral and Consent Divorce. Unpublished manuscript. University of Texas, Department of Economics, Austin.

Wolfers, Justin. 2006. Did Unilateral Divorce Laws Raise Divorce Rates? A Reconciliation and New Results. American Economic Review 96:1802-20.

Wydick, Bruce. 2004. Repeated Games, Marriage, and the Rise of Cohabitation. Unpublished manuscript. University of San Francisco, Department of Economics, San Francisco.

Zelder, Martin. 1993. Inefficient Dissolutions as a Consequence of Public Goods: The Case of No-Fault Divorce. Journal of Legal Studies 22:503-20. 